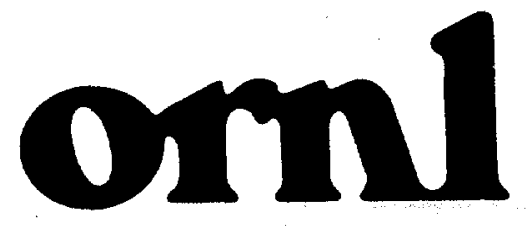

OAK RIDGE

NATIONAL

LABORATORY

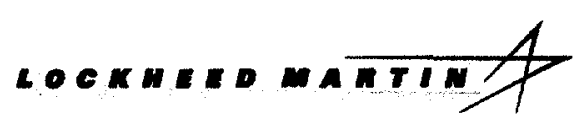

\author{
PERFORMANCE MEASURES FOR \\ EVALUATING PUBLIC PARTICIPATION \\ ACTIVITIES IN DOE's OFFICE OF \\ ENVIRONMENTAL MANAGEMENT
}

Sam A. Carnes Martin Schweitzer Elizabeth B. Peelle Amy K. Wolfe John F. Munro 
ORNL-6905

ENERGY DIVISION

\title{
PERFORMANCE MEASURES FOR EVALUATING PUBLIC PARTICIPATION ACTIVITIES IN DOE's OFFICE OF ENVIRONMENTAL MANAGEMENT
}

\author{
Sam A. Carnes \\ Martin Schweitzer \\ Elizabeth B. Peelle \\ Amy K. Wolfe \\ John F. Munro
}

Ąugust 1996

Sponsored by

Office of Intergovernmental and Public Accountability

Office of Environmental Management

U.S. Department of Energy

\author{
OAK RIDGE NATIONAL LABORATORY \\ Oak Ridge, Tennessee 37831-6285 \\ managed by \\ LOCKHEED MARTIN ENERGY RESEARCH CORP. \\ for the \\ U.S. DEPARTMENT OF ENERGY \\ under Contract Number DE-AC05-960R22464
}




\section{ACKNOWLEDGMENTS}

The authors are grateful for the assistance provided by DOE Field Offices and their Managing and Operating ( $M \& O)$ contractors in helping us arrange interviews with both internal and external stakeholders associated with various EM projects at the nine DOE sites examined in this project. We are especially grateful for the many hours provided by those stakeholders (ranging approximately from one-half to two hours each for over 140 individuals) in responding to questions during our interviews and responding to the written survey. Our approach to developing performance indicators was fundamentally based on evidence in the field - from people who work, in a paid or volunteer capacity, to improve the remediation of contaminated areas and the management of wastes associated with past and current DOE activities and who are instrumental in integrating public participation with those objectives. In addition, we appreciate the efforts of those people who provided timely and critical reviews of an earlier version of this report: Bruce Tonn, Jack Hoopes, Chuck Hundertmark, Beth Oms, Sandy Perkins, Judith Bradbury, Kristi Branch, and Don Beck. Finally, we also appreciate discussions throughout the life of this project and guidance and input from Don Beck, Deputy Director of the Office of Intergovernmental and Public Accountability, Office of Environmental Management, DOE, for what has proved to be a very challenging applied research effort. 


\section{TABLE OF CONTENTS}

ACKNOWLEDGMENTS.

TABLE OF CONTENTS.

LIST OF TABLES

LIST OF FIGURES

vi

EXECUTIVE SUMMARY

Chapter 1 - BACKGROUND, RESEARCH METHODS, AND SCOPE................................. 1

EM Mission and Goals

Objectives-Based Definitions of Successful Public Participation

Research Methods

Scope of Report.

Chapter 2 - EM ACTIVITIES, PUBLIC PARTICIPATION EFFORTS, AND KEY STAKEHOLDERS AT SELECTED DOE FACILITIES

Introduction

EM Activities Examined

Public Participation Efforts

Key Stakeholders.

Description of Attributes Rated by Stakeholders

Stakeholder Responses to Attributes.

Other Possible Attributes

Key Attributes to Use in Future Evaluations.

Chapter 4 - PERFORMANCE INDICATORS FOR KEY ATTRIBUTES.

The Decision-Making Process Allows Full and Active Stakeholder Participation............. 30

The Decision-Making Process Is Accepted as Legitimate by Stakeholders..

DOE and Other Stakeholders Understand Each Others' Concerns.

The Public Has Trust and Confidence in DOE and the DOE Facility

Key Decisions Are Improved by Public Participation.

Key Decisions Are Accepted as Legitimate by Stakeholders.

DOE's Site-Specific Mission Is Accomplished

Chapter 5 - SUMMARY AND RECOMMENDATIONS .............................................. 37

Summary of Key Findings..

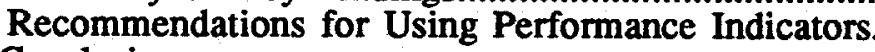

Conclusions

REFERENCES

APPENDIX A. ORAL DATA COLLECTION PROTOCOL............................................ 51

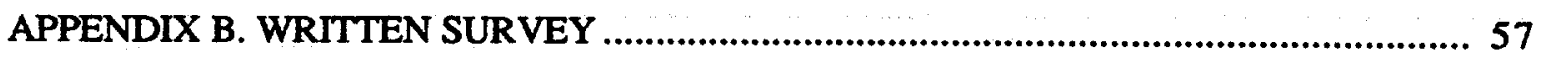

APPENDIX C. LIST OF INTERVIEWEES, BY SITE .................................................. 63

APPENDIX D. KEY PUBLIC PARTICIPATION DEVICES USED AT DOE SITES ......... 69 


\section{LIST OF TABLES}

Table ES.1 Recommended attributes of success, performance indicators, and evaluation techniques. viii

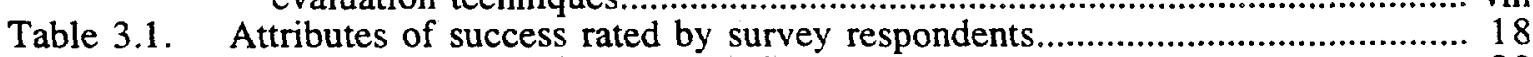

Table 3.2. Mean rating for each attribute of success............................................... 22

Table 3.3. Attributes of success appearing in respondents' "top five" lists most frequently, by organization type................................................ 24

Table 3.4. Key attributes of success to use in future evaluations ................................ 27

Table 5.1. Suggested performance indicators for key attributes of success .................... 38

\section{LIST OF FIGURES}

Fig. 1.1. A decision-making framework incorporating public/stakeholder

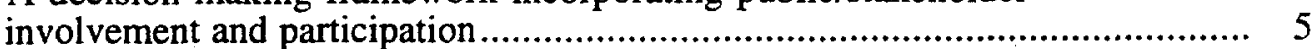

Fig. 1.2. Location of DOE sites for data collection................................................... 7

Fig. 3.1. Distribution of survey respondents, by organization type ............................ 21

Fig. 3.2. Percent of all survey respondents including each attribute of success in their "top five" list ........................................................... 23 


\section{EXECUTIVE SUMMARY}

Public participation activities in the Office of Environmental Management (EM) in the Department of Energy (DOE) have been estimated to have already resulted in substantial cost savings and other improvements for DOE and the nation. This report provides research support to expand those savings and improvements and facilitate other improvements by developing a set of performance-based indicators for use in evaluating public participation programs and activities in EM, with special emphasis on activities implemented in the field.

The value added by public participation to decision-making can be enhanced through better organization, improved participation strategies and mechanisms, and integration with other aspects of decision-making (including integration of stakeholders with problem definition, mission development, the identification and evaluation of decision alternatives, decision-making, and decision implementation). However, the opportunity to improve the value added by public participation is contingent on being able to demonstrate that the resources devoted to such activity is a sensible and worthwhile investment. The Office of Intergovernmental and Public Accountability in DOE's EM is committed to public participation and involvement in decision-making and is seeking mechanisms to demonstrate the worth of that investment to DOE and other decision-makers, as well as to the public and stakeholders themselves.

The attributes and indicators of public participation success identified in this report are designed to facilitate the documentation of the value added by public participation and to provide a mechanism by which decision-makers and public participation specialists can identify strengths and weaknesses of their current efforts so as to do a better job. The attributes and indicators were developed through reviews of appropriate research literatures and significant interactions with stakeholders in the field - through intensive interviews and surveys with DOE project managers and public participation specialists, contractor project managers and public participation specialists, representatives of tribal, state, and local governments, federal and state regulatory authorities, environmental interest groups, and other interested parties. On the basis of variability in geographic location, types of environmental management activities undertaken, the current life-cycle stage of those EM efforts, and the public participation mechanisms used, we selected activities at nine DOE sites with EM activities - the West Valley Demonstration Project in New York, the Wayne FUSRAP site in New Jersey, the Savannah River Site in South Carolina, the Oak Ridge Reservation in Tennessee, the Fernald site in Ohio, the Weldon Spring site in Missouri, the Ambrosia Lake UMTRA site and Sandia National Laboratories in New Mexico, and the Stanford Linear Accelerator Center site in California. We interviewed approximately 140 stakeholders representing the above-named categories in the field or over the telephone and received completed written surveys from 106 of those stakeholders.

Representatives of these internal and external stakeholder groups individually rated attributes, and that rating process demonstrated remarkable agreement both within and across internal and external stakeholder groups. That agreement allowed us to assemble a subset of attributes focusing on the decision-making process, mutual understanding among internal and external stakeholders, trust and confidence in DOE and its local manifestations (i.e., individual DOE facilities, field offices, and activities, projects, and programs), the decisions themselves, and mission accomplishment (see Table ES.1).

The indicators for these attributes, also shown in Table ES.1, were likewise developed with the participation of the internal and external stakeholders at our study sites. Based on 
Table ES.1. Recommended attributes of success, performance indicators, and evaluation techniques

\begin{tabular}{|c|c|c|}
\hline Attribute & Performance indicator & Evaluation technique \\
\hline \multirow[t]{2}{*}{$\begin{array}{l}\text { The decision-making } \\
\text { process allows full and } \\
\text { active stakeholder repre- } \\
\text { sentation. }\end{array}$} & $\begin{array}{l}\text { The proportion of all identi- } \\
\text { fiable stakeholder groups that } \\
\text { have taken part in public par- } \\
\text { ticipation efforts. }\end{array}$ & $\begin{array}{l}\text { Identify all relevant stakeholder groups, de- } \\
\text { termine which ones have been involved in } \\
\text { public participation efforts, and divide the latter } \\
\text { by the former. }\end{array}$ \\
\hline & $\begin{array}{l}\text { The mechanisms used to } \\
\text { attract, engage, and maintain } \\
\text { the interest of stakeholders } \\
\text { throughout the public partic- } \\
\text { ipation effort. }\end{array}$ & $\begin{array}{l}\text { List all mechanisms used to alert and recruit } \\
\text { stakeholders and keep them involved, and } \\
\text { compare with a listing of key public partici- } \\
\text { pation devices used elsewhere. }\end{array}$ \\
\hline $\begin{array}{l}\text { The decision-making } \\
\text { process is accepted as } \\
\text { legitimate by stake- } \\
\text { holders. }\end{array}$ & $\begin{array}{l}\text { Participants' evaluation of the } \\
\text { legitimacy of decision-making } \\
\text { processes at various stages in } \\
\text { the decision cycle for the EM } \\
\text { activity in question. }\end{array}$ & $\begin{array}{l}\text { Ask all individuals involved in the public par- } \\
\text { ticipation process to respond to the following: } \\
\text { "Using the following five-point scale, please } \\
\text { indicate the extent to which the decision- } \\
\text { making process was conducted fairly and served } \\
\text { the broad public interest." a }\end{array}$ \\
\hline $\begin{array}{l}\text { DOE and other stake- } \\
\text { holders understand each } \\
\text { others' concerns. }\end{array}$ & $\begin{array}{l}\text { Internal and external stake- } \\
\text { holders' ability to identify } \\
\text { each others' concerns and } \\
\text { understand the basis of those } \\
\text { concerns. }\end{array}$ & $\begin{array}{l}\text { Ask each participating individual to list the } \\
\text { major concerns of all other stakeholder groups } \\
\text { and to explain the chief objectives and } \\
\text { motivations of these other groups. }\end{array}$ \\
\hline $\begin{array}{l}\text { The public has trust and } \\
\text { confidence in DOE and the } \\
\text { DOE facility. }\end{array}$ & $\begin{array}{l}\text { The public's self-reported } \\
\text { levels of trust and confidence } \\
\text { in DOE and its contractors. }\end{array}$ & $\begin{array}{l}\text { Ask participants and representatives of the } \\
\text { general public to respond to the following: } \\
\text { "Using the following five-point scale, please } \\
\text { indicate the extent to which you have trust and } \\
\text { confidence in DOE officials and associated } \\
\text { contractors to perform their duties in a way that } \\
\text { serves the broad public interest." a }\end{array}$ \\
\hline $\begin{array}{l}\text { Key decisions are im- } \\
\text { proved by public partic- } \\
\text { ipation. }\end{array}$ & $\begin{array}{l}\text { Judgments by internal and } \\
\text { external stakeholders that } \\
\text { public participation has led to } \\
\text { better decisions. }\end{array}$ & $\begin{array}{l}\text { Ask all participants to respond to the follow- } \\
\text { ing: "Using the following five-point scale, } \\
\text { please indicate the way in which important } \\
\text { decisions have been affected by the public par- } \\
\text { ticipation effort(s) in question." } b\end{array}$ \\
\hline $\begin{array}{l}\text { Key decisions are accepted } \\
\text { as legitimate by stake- } \\
\text { holders. }\end{array}$ & $\begin{array}{l}\text { Participants' evaluation of the } \\
\text { legitimacy of decisions for a } \\
\text { given EM activity. }\end{array}$ & $\begin{array}{l}\text { As all participants to respond to the following: } \\
\text { "Using the following five-point scale, please } \\
\text { indicate the extent to which important are fair } \\
\text { and serve the broad public interest." } a\end{array}$ \\
\hline $\begin{array}{l}\text { DOE's site-specific } \\
\text { mission is accomplished. }\end{array}$ & $\begin{array}{l}\text { The development and imple- } \\
\text { mentation of a decision inte- } \\
\text { grating cost, schedule, envi- } \\
\text { ronmental, safety, and health } \\
\text { factors plus other external } \\
\text { stakeholder concerns. }\end{array}$ & $\begin{array}{l}\text { Examine the associated costs, schedule, envi- } \\
\text { ronmental impacts, health and safety implica- } \\
\text { tions, and other important effects, and deter- } \\
\text { mine how well the actions described in the } \\
\text { decision fulfill DOE's site-specific mission and } \\
\text { address the concerns most important to other } \\
\text { stakeholders. }\end{array}$ \\
\hline
\end{tabular}

\footnotetext{
${ }^{a}$ The five-point scale referred to here is constructed as follows: $[1=$ not at all; $2=$ slightly; $3=$ moderately; $4=$ substantially; $5=$ completely].

$b$ The five-point scale referred to here is constructed as follows: $[1=$ very negatively; $2=$ somewhat negatively; $3=$ neither negatively nor positively; $4=$ somewhat positively; $5=$ very positively $\}$.
} 
our request to respondents for suggested indicators of success corresponding to their "top five" attributes, we received hundreds of suggestions. Looking for commonality among the suggestions and opportunities to combine and integrate indicators, we assembled indicators for each of the attributes considered to be useful and important in future evaluations. The use of some of these indicators will require some site-specific or project-specific modification.

The package of attributes and indicators we have recommended should offer a means to document the value added by public participation in EM decision-making in the field and, when aggregated, across all EM activities in the DOE complex. The package should also be useful in identifying areas of strength and areas where improvements can be made in implementing a high-quality public participation program.

Evaluators should be cautioned, however, that the attributes and indicators are interactive, and a thorough evaluation requires the whole package. For example, the legitimacy of the decision-making process is affected by the extent to which full and active representation of stakeholders is accomplished. Similarly, a "high quality" decision requires consideration of all factors leading to a decision where the simultaneous accomplishment of "better-faster-cheaper" can be achieved without sacrificing any of those three criteria. This caution leads to a complementary and equally important concern - any evaluation of the success of public and stakeholder participation should represent the varied perspectives offered by our multiple attributes and indicators. Success cannot (or should not) be ranked or aggregated to a single score because that would deny the multi-dimensionality of the concept of success. Furthermore, we acknowledge that there may be some cases that call for one or more additional attributes or indicators not recommended in this report, and there may be some cases where an evaluator wants to evaluate some attributes more frequently than others because of a perceived need to "fix" some part of a public participation activity or program.

This report also suggests evaluation techniques to use when measuring the success of public participation programs in terms of the recommended attributes and performance indicators (see Table ES.1). The suggested methods are drawn from the program evaluation and decision-making literatures, interviews with stakeholders, and the past research experience of the authors. 


\section{CHAPTER 1. BACKGROUND, RESEARCH METHODS, AND SCOPE}

Public participation in decision-making in the United States has become a dominant theme throughout the public sector and is increasingly used in the private sector. Recent reports by the National Research Council and the Commission on Risk Assessment and Risk Management, set up jointly by the White House and Congress, conclude that risk decisions must increasingly be structured in such a manner as to involve stakeholders ${ }^{1}$ meaningfully in the processes and activities leading to decisions and, perhaps, through decision implementation (Phibbs 1996). According to Phibbs (1996:235), both of these reports indicate that

decisions may take longer but be better if officials: 1) bring all interested and affected parties to the table at the beginning of the risk-discussion process; 2) identify relevant concerns, losses, exposures and other information the parties have; 3 ) address significant concerns through appropriate research; and 4) present findings in an understandable, accessible way.

Thus, the task before decision-makers, and the public participation professionals who assist them, is increasingly recognized as a vital part of our common efforts to resolve national and sub-national problems.

Public participation activities in the Office of Environmental Management (EM) in the Department of Energy (DOE) have been estimated to have already resulted in substantial cost savings and other improvements for DOE and the nation. This report provides research support to expand those savings and improvements and to facilitate other improvements by developing a set of performance-based indicators for use in evaluating public participation programs and activities in EM, with special emphasis on activities implemented in the field. The authors hope that these indicators will be useful in any subsequent evaluation of public participation programs and activities performed by EM's Office of Intergovernmental and Public Accountability or by field offices, as efforts are made to enhance public participation programs and activities, improve their effectiveness, and reduce costs of both public participation and environmental management programs for DOE.

By developing technically sound performance-based indicators to measure the effectiveness of public participation activities and identify where improvements might be made, EM should be able to enhance its ability to:

- engage its stakeholders more effectively;

- comply with existing and future legal and regulatory requirements [e.g., the National Environmental Policy Act (NEPA), the Resource Conservation and Recovery Act (RCRA), the Comprehensive Environmental Response, Compensation, and Liability Act (CERCLA), the Federal Facility Compliance Act (FFCAct), and other statutes and associated compliance agreements affecting the DOE complex];

- develop and implement programs and technologies acceptable to the diversity of DOE stakeholders; and

\footnotetext{
1 In this report, we refer to the various individuals and groups who have an interest in the outcome of a particular decision as "stakeholders." This term applies whether or not the interested person or group is directly involved in a given public participation effort. We can distinguish among participating and nonparticipating stakeholders, as well as among "internal" and "external" stakeholders. For EM activities, projects, and programs, internal stakeholders are DOE and its contractors, while external stakeholders encompass the broad range of other interested parties.
} 
- reduce total program costs $^{2}$ for environmental management.

This report, prepared for the Office of Intergovernmental and Public Accountability of $\mathrm{EM}$, is intended to facilitate subsequent evaluations of public participation activities and programs for both the DOE complex as a whole as well as for individual field offices, sites, and projects.

\section{EM MISSIONS AND GOALS}

The primary EM program mission is to protect human health and the environment. EM is organized around four central functions -- waste management, environmental restoration (including remedial actions and decontamination and decommissioning of surplus facilities), technology development, and facility transition and management. These functions are implemented at Headquarters and field sites and are guided by six goals that EM has identified to accomplish its mission:

- eliminate and manage urgent risks in DOE's system;

- emphasize health and safety for DOE workers and the public;

- establish a system that is managerially and financially in control;

- demonstrate tangible results;

- focus technology development efforts on identifying and overcoming obstacles to progress; and

- develop a stronger partnership between DOE and its stakeholders.

EM's implementation of its mission and functions is particularly difficult in light of a number of challenges currently facing the office. These challenges include:

- converting the nation's largest industrial complex from defense nuclear materials production to environmental management;

- replacing a legacy of secrecy and mutual distrust between DOE and its stakeholders with a relationship characterized by open communication and mutual trust and respect;

- developing and using safer and more cost-effective waste management, remediation, decontamination, and decommissioning technologies;

- establishing consensus definitions of what "clean" means, and setting standards for assessing when a site is clean;

- working with stakeholders to define and understand risk management and to integrate risk and "how clean is clean" determinations in deciding the future use of surplus DOE sites; and

- making difficult decisions, with stakeholder input, that balance budget constraints with other important objectives while simultaneously solving regulatory conflicts.

2 Total costs for virtually any future activity are subject to revision as new information is obtained. Thus, early estimates may be erroneously low (or high) due to "inaccurate" characterizations of a problem and alternative solutions. 
The range and complexity of problems facing EM, and the decisions that must be made to solve these problems, are considerable. They may range from how to decontaminate a single building at a single site and remediate environmental contamination resulting from activities in that building to managing and disposing of DOE's spent nuclear fuel throughout the entire complex.

Resolving these problems is made even more problematic by the fragmented nature of the institutional environment in which EM operates. Part of this institutional environment, the federal governmental system, has multiple layers of national, state, tribal, and local government agencies and other representatives (e.g., U.S. Congress and state, tribal, and local legislative and regulatory bodies) with varying levels of influence and authority over DOE decision making. In DOE's case, its approximately 130 sites with environmental restoration and/or waste management operations are located in 32 states and Puerto Rico. Although in many cases DOE may be able to deal with a single state, tribal, or commonwealth government at a time, whenever DOE anticipates inter-site activities, coordination, consultation, and regulatory requirements expand significantly.

In addition to those stakeholders with constitutional or statutory responsibilities and authorities, EM acknowledges that its stakeholders include: environmental groups; labor unions; community organizations; citizens, including Native Americans, who live near DOE sites or in the same state; other interested members of the public; and every taxpayer in the nation. Although these groups and individuals do not have legal authority over DOE decision making, EM recognizes these stakeholders as important participants in its decision making.

\section{OBJECTIVES-BASED DEFINITIONS OF SUCCESSFUL PUBLIC PARTICIPATION}

As identified in various publications of the Office of Intergovernmental and Public Accountability, the objectives of EM's public participation programs, plans, and activities include:

- soliciting the public's help in identifying EM problems and related issues;

- soliciting the public's involvement in identifying a full range of approaches for addressing these problems and issues;

- increasing public understanding of the complex environment in which DOE operates; and

- facilitating a broad-based consensus on EM's objectives and how to achieve those objectives.

Determining whether an activity has succeeded is often problematic. Such a determination depends fundamentally on how success is defined and how one determines or measures whether that definition has been satisfied. For its part, EM has stated that it believes that successful public participation will result in decisions that:

- are technically feasible;

- are economically feasible;

- are environmentally sound;

- are health and safety conscious;

- address public concerns and values; and 
- can be implemented.

While these decision outcomes might be reasonable as a "long-term" definition of success, uncertainties regarding the lag times and causal pathways associated with these concepts make their measurement difficult in the short term. Moreover, this outcomeoriented definition of success may or may not be consistent with the views of EM's diverse stakeholders (see above). These stakeholders might accept some or all of the components of EM's definition, but might also include other procedural as well as substantive elements. They might include issues such as (1) winning and securing as many objectives as possible for themselves (i.e., self-interest); (2) getting a fair settlement and "having things come out right" (i.e., distributive justice); and/or (3) having the problem resolved through a procedure they view as fair (i.e., procedural justice). In short, these stakeholders may define success in terms of their principal objectives and agendas and may be more or less sensitive to EM's multiple objectives. In this report, we refer to each possible definition of success as describing a specific "attribute" of successful public participation efforts.

Developing performance-based indicators of public participation program success for EM activities is influenced not just by the key attributes of success on which we choose to focus but also by how the major problems are stated. As indicated in Fig. 1.1, public participation is embedded within particular problems and their contexts and within associated decisions and their contexts. Although DOE/EM can and does structure problems, decisions, and their contexts for its stakeholders prior to their involvement, it is important to understand and assess the extent to which internal and external stakeholders have common conceptions of what the problem is and how it relates to other problems and what decision needs to be made and how it relates to other decisions.

Decisions obviously can be and have been made by DOE and other agencies without explicitly or proactively incorporating stakeholder concerns. Thus, decisions could be made without the non-regulatory stakeholder involvement shown in Fig. 1.1, although agencies have historically been required to incorporate input from regulatory agencies. In the context of current EM and DOE policy, however, the decision making framework can be envisioned as shown in Fig. 1.1 with the full accompaniment of public participation activities and outcomes. Once these activities have been completed and stakeholder concerns have been considered by the decision-making authority, a decision is rendered (i.e., decision output) and implemented. Once implemented, the outcome of the decision is monitored to determine if the decision and its implementation resolved the problem at hand; if necessary, the decision and implementation are adjusted through feedback loops. Of course, it is possible that the initial decision (or proposal) cannot be implemented if sufficient opposition to the decision emerges.

\section{RESEARCH METHODS}

The basic approach taken in this effort was to ask internal and external stakeholders to help identify attributes of successful public participation in EM activities and to elicit their ideas and suggestions regarding how those attributes might be measured. Prior to eliciting comments from stakeholders, we conducted a review of the relevant literatures to see how the success of public participation efforts had been measured in previous evaluations and to help identify the key stakeholder groups to interview. Sources included DOE reports (e.g., U.S. DOE 1994a; U.S. DOE 1994b; U.S. DOE 1994c) and a variety of other professional and academic publications (e.g., Beck, Kelly, and Forbes 1995; Lach, Hixson, and Ramonas 1995; Maguire 1995; Rosener 1978; Syme and Sadler 1994; Young, Williams, and Goldberg 1993; and other references cited throughout the report). 


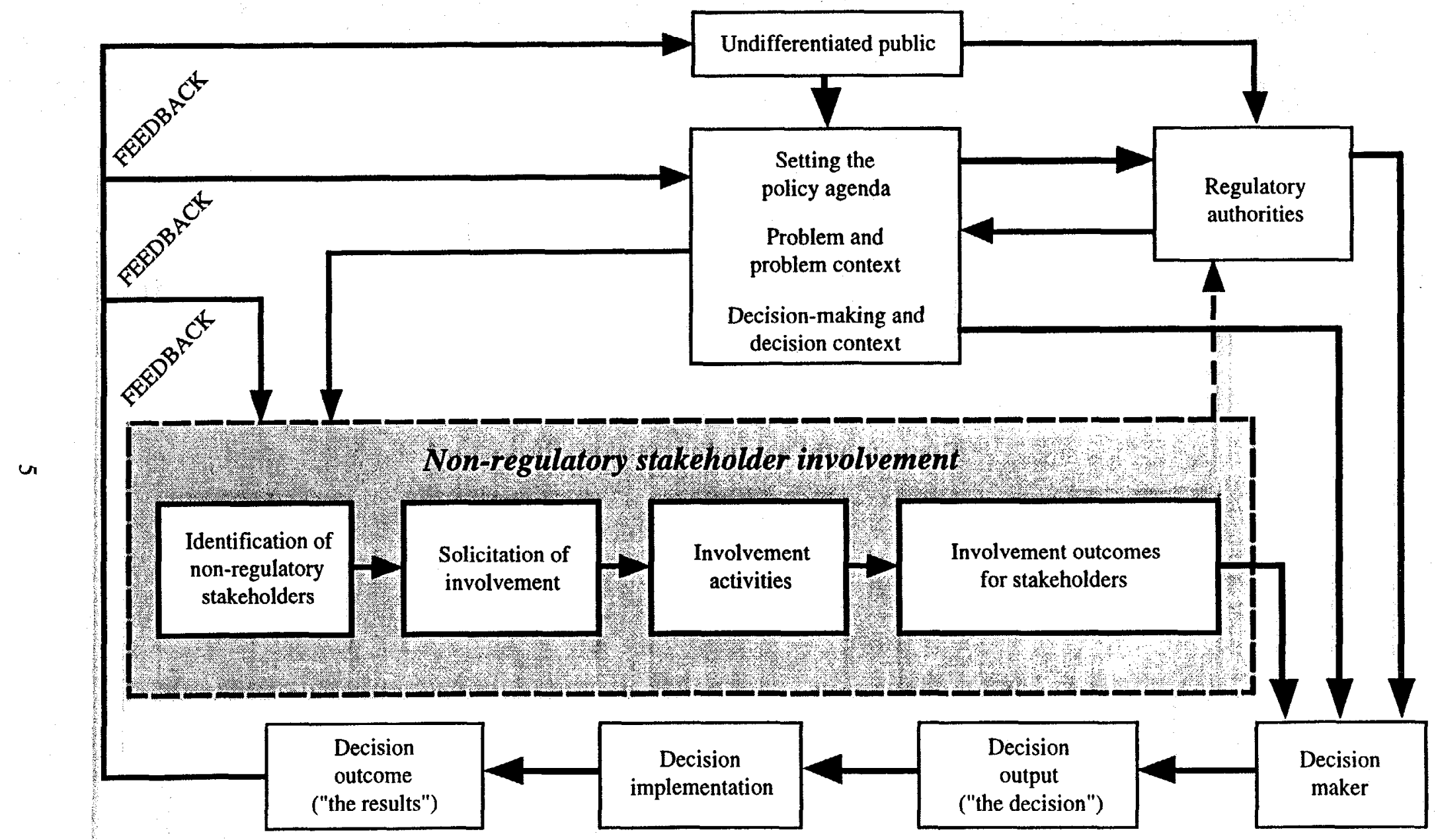

Fig. 1.1. A decision-making framework incorporating public participation. 


\section{Performance Measures for Evaluating Public Participation Activities in DOE's Office of Environmental Management}

The DOE sites that we selected for this study were chosen to provide substantial variety in terms of geographic location, types of environmental management activities undertaken, the current life-cycle stage of those EM efforts, and the public participation mechanisms utilized. Background information on potential study sites - upon which the selection process was based - came from published reports (U.S. DOE 1995a, U.S. DOE 1995b) and discussions with knowledgeable professionals familiar with DOE's EM activities.

Five DOE facilities were selected for intensive site visits: the Fernald Environmental Management Project (FEMP) in Ohio; the Savannah River Site (SRS) in South Carolina; the Oak Ridge Reservation (ORR) in Tennessee; the Sandia National Laboratories (SNL) in New Mexico; and the Ambrosia Lake Uranium Mill Tailings Remedial Action (UMTRA) project, also in New Mexico. In addition, telephone interviews were conducted with key stakeholders at four additional sites: the Weldon Spring Site Remedial Action Project in Missouri; a Formerly Utilized Sites Remedial Action Program (FUSRAP) site in Wayne, New Jersey; the Stanford Linear Accelerator Center (SLAC) in California; and the West Valley Demonstration Project in New York. The EM sites examined in this study are shown in Fig. 1.2.

At each site, our research efforts focused on the entire range of public participation efforts associated with a specific EM activity or logically connected set of activities. At the Savannah River Site, we examined the public participation efforts that addressed the remediation of groundwater contamination at the $\mathrm{F}$ - and $\mathrm{H}$-area seepage basins. In Oak Ridge, we focused on the activities of the working group that addressed remediation of offsite mercury contamination of the Lower East Fork Poplar Creek. At Sandia National Laboratories, we investigated stakeholder involvement associated with the consolidated treatment, storage, and containment of hazardous wastes in the Corrective Action Management Unit and Treatment Unit (CAMU and TU) project. At the West Valley site in New York, that is owned in part by the federal government (DOE) and in part by the State of New York, we looked at the DOE portion of the site - the West Valley Demonstration Project - in terms of cleanup and public participation. Our focus at SLAC was on the removal of polychlorinated biphenyls (PCBs) from the IR-G drainage channel. At the Wayne (NJ) FUSRAP site, we focused on public participation associated with remediation of the aboveground interim storage pile containing site- and vicinity property wastes and below-ground contamination. Above ground (surface) site cleanup and decommissioning was the focus of our study at the Ambrosia Lake UMTRA site, In contrast, our work at the Weldon Spring, and the Fernald sites - where the facilities' single current mission is decommissioning focused on the overall clean-up effort.

The key stakeholder groups from which we chose representatives to interview at the study sites include the following:

- DOE project managers and public participation staff (variously called community relations, public affairs, public information, and other titles);

- Project managers and public participation staff for the Management and Operations (M\&O) contractor managing the case study facility for DOE (e.g., Lockheed Martin Energy Systems at Oak Ridge);

- Federal and state environmental regulators (e.g., the U.S. Environmental Protection Agency and state departments of health or environmental protection - typically one of the state permitting agencies);

- Native American tribal governments; 


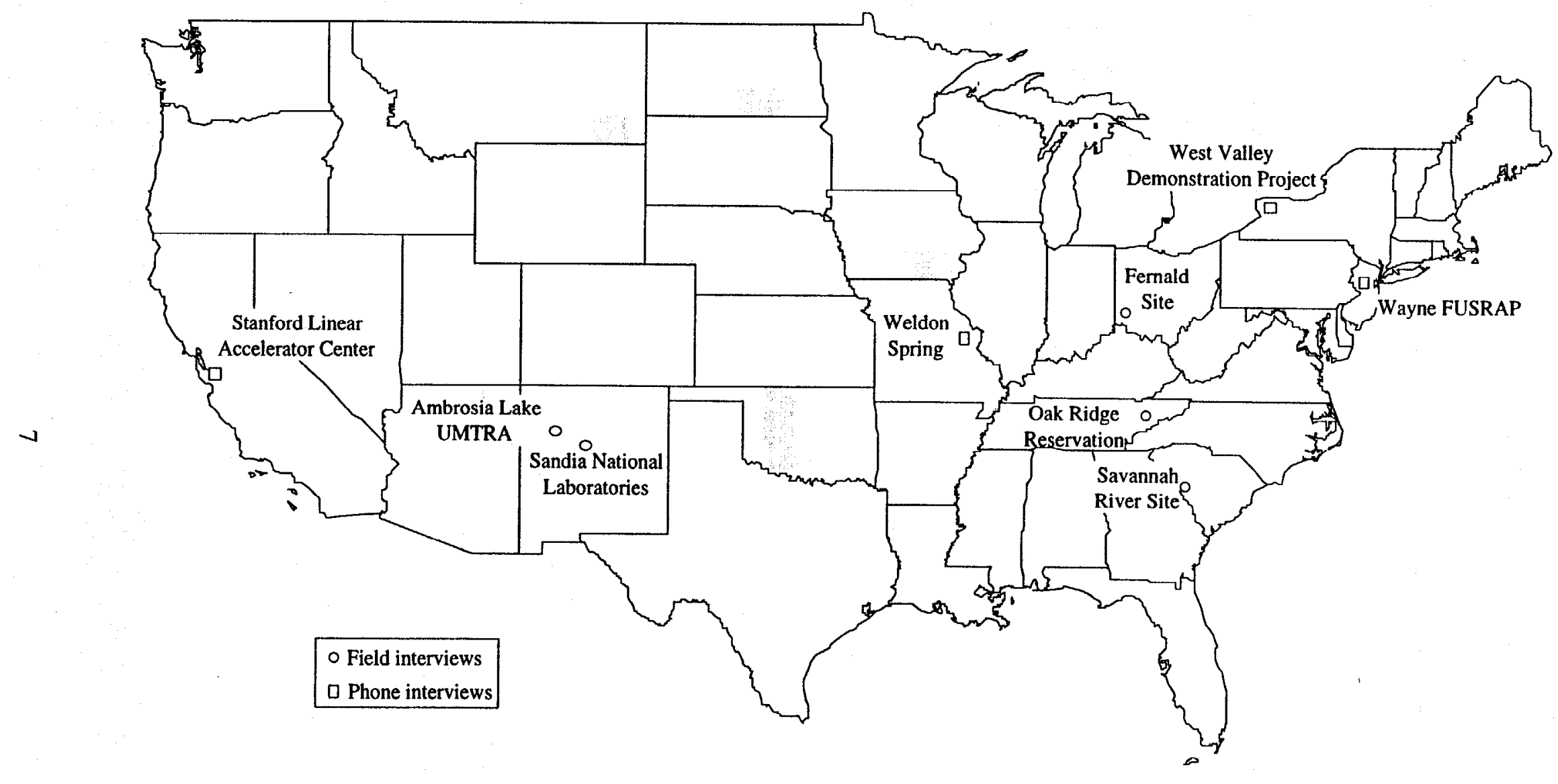

Fig. 1.2. Location of EM sites for data collection. 


\section{Performance Measures for Evaluating Public Participation Activities in DOE's Office of Environmental Management}

- State and local government officials (e.g., elected office-holders, paid staff, and appointed board members);

- Non-government groups concerned with environmental protection, public safety, and health issues;

- Business organizations (e.g., local chambers of commerce);

- Civic clubs and organizations (e.g., the League of Women Voters);

- Labor unions;

- Owners of property near the facility with a direct financial stake in the outcome of the EM activity; and

- Other interested parties.

This purposive sample, focusing on types of participants who are typically involved in environmental decision-making processes rather than on representatives of the general public or other social groupings, was selected to provide variation in stakeholder types ${ }^{3}$ and to make the most effective and efficient use of research resources. This sampling approach does not, by and large, attempt to address the inputs of non-participating stakeholders (e.g., through random sample survey methods).

Based on the literature review and prior professional experience, we designed an openended oral data collection protocol to use during the first two site visits to Fernald and Savannah River. Using the information gathered at these sites in late October and early November of 1995, we refined the open-ended oral protocol (see Appendix A), designed a supplemental written survey (see Appendix B), and used these new instruments to collect data from stakeholders at all subsequent sites. We also sent the written survey to all respondents previously interviewed at Fernald and Savannah River so that we would have comparable data for all sites. ${ }^{4}$ The written survey was designed to elicit respondent preferences to specific attributes of success (see Chapter 3) and to extract information regarding potentially appropriate performance indicators to use in measuring the extent to which public participation efforts had been successful according to those attributes (see Chapter 4).

We found that approximately 12 to 15 interviews were necessary to cover each site adequately. We learned that many fewer than 12 interviews would not provide sufficient information to allow us to characterize the EM activity from multiple stakeholders' perspectives, and many more than 15 interviews resulted in simple confirmation of the characterizations we obtained from previous interviewees. Each interview conducted in the field lasted approximately one to two hours, while those conducted on the phone lasted approximately 30

\footnotetext{
${ }^{3}$ This sampling approach is conceptually similar to those used in numerous policy analyses (see, for example, Bardach 1977; Lowi, Ginsberg, et al. 1976; Pressman and Wildavsky 1973; and Rochefort and Cobb 1994). A study of the relationships between decision-making and the participation of other kinds of groups (e.g., based on gender, income, education, and/or cultural affinity) or of the general public might reach different conclusions than evidenced in this report.

4 Preliminary suggestions for definitions (later called attributes) of successful public participation were elicited from interviewees at SRS and Fernald and combined with elements identified in research literatures from political science, sociology, and program evaluation, among others. These definitions or attributes were reviewed and adapted for use in the written survey, where opportunity was also provided for respondents to identify any other definitions or attributes of successful public participation.
} 
minutes to one hour. A complete listing of all interviewees, organized by site and showing their primary organizational affiliation, is provided in Appendix C.

\section{SCOPE OF REPORT}

This report, and the research from which it was prepared, addresses public participation activities associated with specific EM activities and projects at a purposive sample of DOE sites in the continental United States. It focuses on public participation in the context of decision making and decision outcomes. It asks and answers the question - "How should we measure the success, or lack of success, of public participation activities for [name your EM activity or project]?" This report is especially directed at those internal and external stakeholders in the field who are trying to solve some very vexing problems. The attributes of successful public participation and performance indicators to measure the extent to which success has been achieved were developed from our research and are presented in this report. They are intended to be applicable throughout the DOE/EM complex and its range of activities.

Chapter 2 describes the EM activities and public participation activities and programs that we examined and discusses the key stakeholder groups involved in those efforts. In Chapter 3, we discuss a large number of possible attributes of public participation program success and suggest seven key attributes to use in future evaluations. Chapter 4 suggests appropriate performance indicators to use to measure the extent to which success was achieved according to each of our recommended attributes. Finally, Chapter 5 summarizes our key findings and provides recommendations concerning how to use the aforementioned performance indicators in future evaluations of EM's public participation activities. 


\section{CHAPTER 2. EM ACTIVITIES, PUBLIC PARTICIPATION EFFORTS, AND KEY STAKEHOLDERS AT SELECTED EM FACILITIES}

\section{INTRODUCTION}

Public participation encompasses a diversity of goals and occurs in numerous forms. At a single site, there are often differing expectations among the various stakeholder groups concerning how public participation should take place and what it should achieve. Public participation performance indicators simultaneously need to be sensitive to these kinds of variation and to be applicable across the range of DOE sites. To help understand the diversity among sites and the public participation dynamics within sites, we undertook nine case studies. The overall purpose for these case studies was to provide real-world grounding for the development of performance indicators.

This chapter characterizes the cleanup and waste management activities, public participation efforts, and key stakeholders at the nine sites we investigated. Since our charge was to devise performance indicators for evaluating future public participation efforts at all of DOE's EM sites (currently about 130), we sought a wide range of sites and activities. Sites and projects were selected to achieve wide variation in physical size, geographical location, stage of completion of EM activities, site ownership, size of budget, single project vs. multiproject sites, on- vs. off-site decontamination projects, public participation activities, and regulatory arrangements. Our focus was not upon the full range of EM activities at a given site but rather upon a single activity, project or program.

The EM activities chosen involve eight stages of the nuclear fuel cycle and other activities of the nuclear weapons complex. These stages and activities included uranium mining and milling, uranium fuel refining and processing, warhead fuel and target fabrication and machining, other weapons manufacturing and engineering operations, tritium production, and nuclear fuel reprocessing. Both chemical and radioactive contamination occurred from wastes produced.

The public participation activities studied represent varying levels of involvement or intensity and were carried out in a variety of regulatory and program frameworks. These included actions taken by the U.S. Environmental Protection Agency (EPA) and states with delegated authority related to the Resource Conservation and Recovery Act (RCRA) and the Comprehensive Environmental Response and Liability Act (CERCLA) as well as one project each from the Uranium Mill Tailings Remedial Action (UMTRA) program and the Formerly Utilized Sites Remedial Action Program (FUSRAP), and the West Valley Demonstration Act of 1980.

Governmental settings and frameworks likewise vary. While most sites are federally owned, two are owned wholly or in part by states (the West Valley site in New York and the Ambrosia Lake site in New Mexico). Cooperative relationships between state and federal agencies occur in Tennessee, Missouri, New York, and Ohio. Moreover, state regulation is a significant factor in most, if not all, cases. Local government involvement varies from marginal to major.

\section{EM ACTIVITIES EXAMINED}

The nine sites represented different stages of environmental remediation and waste management, including: planning, studying, and organizing for cleanup or waste management; decision making; actual cleanup or waste treatment, storage (including containment); completion and closure; and disposal. They also displayed a range of objectives in addition to the principal one of cleaning up or managing whatever contaminants were at issue. 


\section{Performance Measures for Evaluating Public Participation Activities in $D O E$ 's Office of Environmental Management}

Four sites were moving from study to removal actions: the CAMU at Sandia National Laboratories in New Mexico; cleanup of the Fernald Environmental Management Project in Fernald, Ohio; the Lower East Fork Poplar Creek on the Oak Ridge Reservation (ORR); and the $\mathrm{F}$ and $\mathrm{H}$ groundwater project at the Savannah River Site (SRS). Both West Valley and Fernald are planning vitrification of their high level wastes. Two other sites had taken partial actions and were in between action stages [Stanford Linear Accelerator Center (SLAC) in Stanford, California, and the FUSRAP site in Wayne, New Jersey], while a third site (Weldon Spring) is actively engaged in an ongoing clean-up process. Cleanup was essentially complete at one other site: Ambrosia Lake had celebrated the site closing after surface cleanup (Phase I) in September, 1995. It should be noted that often the planning and study phases had taken years and required significant resources, as is true of many if not most cleanup actions at federal facilities.

Many different types of waste management actions were planned or underway. Containment of existing wastes to prevent their movement or further dispersion was of high priority, as when the UMTRA project site manager moved to cap old uranium mine openings and ventilation shafts to prevent further radon emissions. The pump and re-injection approach chosen at SRS in the $\mathrm{F}$ and $\mathrm{H}$ Groundwater project was designed specifically to contain and delay the tritium from entering the river, thus allowing more radioactive decay in the process.

On-site disposal or containment were the principal waste management modes, with engineered landfills, engineered containment cells, and special covers the favored options. Soils had been scraped and sometimes treated, and dumps had been excavated and removed to designated sites. Buildings were demolished and buried with other debris and contaminated soils in the Weldon Spring Site Remedial Action Project in Weldon Spring, Missouri, and the Ambrosia Lake site in New Mexico. Site selection ranged from being a major action at Sandia National Laboratories, involving stakeholders in a CAMU Working Group for identifying a site for a containment cell, to a non-issue at Oak Ridge where the offsite contamination was slated for on-site re-burial.

Off-site disposal was a major issue at the FEMP and the Wayne FUSRAP project. At Fernald the Citizen Advisory Board (CAB) accepted the DOE plan, which stated that only higher level wastes should be shipped off-site, agreeing to on-site disposal of lower level radioactive and other chemical wastes. In the Wayne FUSRAP case, off-site contaminated by thorium were moved to an on-site pile near the town. While a decision has been made to dispose of the above-ground pile formed by the clean-up of vicinity properties off-site, the disposition of the below-ground waste is in dispute. At SLAC, PCB-contaminated soils were removed and disposed off-site without controversy.

Surface water runoff and watercourse contamination were issues at SRS and the ORR. Pump and re-inject was the chosen technology at SRS in accordance with a record of decision (ROD) in 1992. This method of treatment was challenged by SRS supporters and the Citizen Advisory Board (CAB) when the EPA reopened the issue in 1995. The CAB was formed in part because of adverse reactions by Savannah residents 100 miles downstream to the tritium spill into the Savannah River from a SRS reactor a few years before.

In Oak Ridge, the Lower East Fork Poplar Creek (LEFPC), which runs through the city of Oak Ridge, is contaminated by mercury lost from the Y-12 weapons plant in past decades. The LEFPC Working Group's input altered the scope of the proposed treatment of digging up tons of dirt and trees in the watershed for deposit in a secured on-site landfill. A reduced program of dirt removal has been promulgated in the October, 1995 ROD.

Groundwater contamination has occurred at several sites but was most prominent at FEMP, which is located directly over the principal area water source, the Great Miami Aquifer. Various remediation methods are under consideration, including creating barriers by freezing to prevent further movement. Bottled water was supplied to area residents whose wells were contaminated by uranium until a new water supply system could be constructed in 


\section{Performance Measures for Evaluating Public Participation Activities in DOE's Office of Environmental Management}

1995-1996. UMTRA sites like Ambrosia Lake will address groundwater contamination in Phase II of the cleanup, for which a Draft Programmatic Environmental Impact Statement (PEIS) was issued in mid-1995.

Cleanup objectives in these cases always included meeting all applicable regulations. In some cases, the aim was also to allow some or all of the site to be reused for other purposes.

The sites displayed a variety of management arrangements. Two sites were wholly or partially owned by states: the Ambrosia Lake UMTRA site in New Mexico and the West Valley Demonstration Project in New York. Both DOE and the State of New York exercised control over their respective areas, while another agency in the state regulated DOE's activities at West Valley. DOE usually shared management and activities with its prime contractor on a given site, though the exact details varied.

Likewise, a variety of regulatory regimes was observed at the sites. In most cases, both regional EPA offices and the relevant state regulatory authority were involved in RCRA and CERCLA actions. NRC was involved at West Valley because of the high level radioactive wastes to be vitrified, while South Carolina was empowered to regulate tritium discharges. The CAMU project at SNL was unique in that it was the first application by DOE (and the State of New Mexico) of the accelerated permitting and cleanup enabled by the EPA's CAMU and treatment unit (TU) regulatory innovations for environmental restoration activities. Some local governments were active at their sites, seeking to influence regulatory decisions through their participation in various forums.

The question of prioritization of particular cleanup projects remains a sticky one not only for multi-project sites such as SRS, ORR and SNL, but also for smaller, single project efforts. Risk levels and their designation, Congressional budgeting, and public participation all can influence where a particular project falls on priority lists, and, thus its year-to-year funding level. Few sites had the luxury of being able to focus solely on one problem - most were attempting to deal with multiple problems and projects simultaneously.

\section{PUBLIC PARTICIPATION EFFORTS}

We found a wide variety of public participation mechanisms and approaches at the nine sites, as well as a variety of effects of those efforts on cleanup and waste management decisions. Respondents saw a variety of connections between public participation and the decision-making process, but they were in remarkable agreement across sites on what constitutes a "success", as will be seen in Chapter 3.

The public participation mechanisms and strategies used at the nine sites included public meetings, workshops, tours, and distribution of information via many channels, as well as more intensive and/or long-term mechanisms such as working groups and citizen advisory boards.

Three sites used a formalized one-on-one strategy for some or all of the external stakeholders (Ambrosia Lake, FEMP and West Valley) but used different mechanisms to implement this strategy. The Ambrosia Lake effort exemplifies the simple inform-andupdate approach in conjunction with a one-on-one strategy. A more elaborate example of one-on-one interactions is the Envoy program at FEMP. In this program employee volunteers undertake training and serve as personalized information carriers, on a long-term basis, between the facility and local organizations and officials.

In a more intensive, iterative consultation mode, projects at two sites used citizen working groups to focus their public participation activities (the CAMU project at $\mathrm{SNL}^{5}$ and the LEFPC project at the ORR), while two others relied upon their more formal site-specific

\footnotetext{
${ }^{5}$ The CAMU project also used the Citizen Advisory Board ( $\mathrm{CAB}$ ) and received $\mathrm{CAB}$ endorsement.
} 


\section{Performance Measures for Evaluating Public Participation Activities in DOE's Office of Environmental Management}

advisory boards or CABs to give advice (the F- and H-groundwater project at SRS and overall restoration efforts at FEMP). Both the CABs and working groups illustrate a more intensive interaction process involving input to decision-making. Special efforts were made by some DOE and public affairs personnel to tailor the level of public participation to the interest level of particular stakeholders (Ambrosia Lakc, FEMP, and West Valley).

Court actions at two sites had preceded current public participation activities, leaving their imprint on the character of current citizen interactions (FEMP and West Valley). In both cases some of the plaintiffs are still actively involved at their sites. The West Valley Nuclear Coalition's mid-1980s lawsuit was resolved out of court with requirements for DOE to provide for citizen notification, information sharing, quarterly meetings, and an EIS on vitrification rather than an EA. These requirements preceded what has become more common practice in public participation throughout the DOE complex in the 1990s.

We asked each responding stakeholder at the nine sites to rate the success of the public participation program at their site on a scale of 1 (lowest) to 5 (highest). The average rating of public participation success for all sites combined was 3.88 or "good" (assuming that the middle value of 3 is seen as "average"). This is an aggregate rating based on all responses, and it does not refer to any individual site or program. We found interesting results when we took our analysis further and disaggregated respondents' ratings by their primary organizational affiliation. Average success scores calculated in that manner ranged from a high of 4.40 for civic organizations to a low of 3.55 for environmental groups. In addition to environmental groups, those rating the success of their public participation efforts as relatively low included business representatives (3.60), state and local governments (3.74), and environmental regulators (3.77). On the higher end of the scale, civic organizations were joined by DOE (4.20), nearby property owners (4.20), and DOE's contractors (3.98). These disparate scores show that, at least when the attributes of success are undefined, different groups have a tendency to view the same efforts through very different lenses. This difference, in turn, highlights the need to get the perspectives of all participating groups when measuring success and to develop systematic methods to elicit these perspective, incorporating the varying viewpoints of all external and internal stakeholders.

Interesting findings resulted when stakeholders were asked to identify the connections, if any, that they saw between public participation and EM decision-making at their site. Different sites have different "footprints" on this issue. The effects of public participation on the conduct of EM programs or EM site decisions varied from none to various reformulations or changes of emphasis to distinct changes or alterations in decisions. Differences within a given site can sometimes be explained by other contextual factors reflected in the interviews. For instance, DOE and contractor staff for one site answered a firm "Yes, there is a connection" as they cited events in related programs at other sites, but external stakeholders at that site did not answer this question at all or said "not much connection," reflecting what all stakeholders agreed upon - that there wasn't much public participation or interest at their site. Slightly over half of the respondents reported that public participation had a direct influence on EM decisions, although there were differences of opinion concerning how strong that influence actually was. Some characterized public participation as being a major driver of EM decisions, some described a less intense connection, and a few said that public participation had too much influence. Another onefifth of those responding to this question said that public participation had very little influence on EM decisions, or that the connection was vague or uncertain, and almost as many respondents expressed the opinion that public participation did not influence EM decisions at all.

\section{KEY STAKEHOLDERS}

At all sites, we interviewed similar sets of internal and external stakeholders. These stakeholders included DOE and contractor project management and public participation staff (staff dedicated to and trained in public affairs, community relations, and/or public 
involvement), Native American tribal authorities, local and state government officials, state and federal regulators, members of the local business and civic communities, property owners of affected lands, members of environmental groups and miscellaneous others who were active in or affected by the EM project.

We defined the internal stakeholders as those employed by DOE or its contractors. Such stakeholders can be further grouped as project management staff, technical staff, and public participation staff (see above).

While we grouped local and state government officials together for analytical purposes, they played somewhat different roles in the public participation efforts studied. State officials and some local government staff participated in some sort of oversight or information role, often in an ex-officio capacity, simply as an added function of their employment. If they held elected posts, local government officials participated as volunteers and spokespersons for their constituencies. These local officials included mayors, city and county managers, heads of relevant agencies (e.g., public health, environmental management), township supervisors, and county commissioners. Health and safety concerns and local economic development tended to be their primary goals.

State and federal regulators participated both in information-giving and informationreceiving roles, as well as in their regulatory capacity. They were active participants in the working groups, for instance, and also, to some extent, in the citizen advisory groups. They were usually at a greater distance, both physically and in terms of social interaction, in their regulatory roles. Since EPA strongly supports public participation in cleanup decision making, EPA representatives tended to be supportive of any public involvement efforts they viewed as properly proactive. Some regulators sponsored separate public participation efforts on the same projects to fulfill RCRA or CERCLA requirements.

Business interests played active stakeholder roles at several sites. They supported cleanup efforts for the jobs and business potential they presented. At two sites they worked actively to keep the facility(ies) open regardless of their cleanup status.

Environmental groups included local, state, and national organizations that participated in EM activities, sometimes on an extended basis as has the West Valley Nuclear Coalition in New York and the Southwest Research and Information Center in New Mexico. In contrast, more recently formed organizations at the SRS have become actively involved in the CAB and its formation with concerns regarding environmental justice.

Civic organizations included the League of Women Voters and neighborhood associations. Property owners were involved in cases of off-site contamination as was the case for LEFPC at the ORR and for cleanup at FEMP. A few stakeholders did not fall into any of our designated categories so they were classified as "other". When individuals fit in multiple categories - such as business and local government, or property owner and environmental organization - we made judgments as to which category was most appropriate for that individual, based on what we saw as their primary organizational affiliation.

We found some very interesting differences among key stakeholder groups in terms of how they perceived the connections between public participation and EM decisions. Among DOE and its contractors, large majorities of the respondents reported that public participation had a direct influence on EM decisions, either serving as a major driver of those decisions or exerting a partial influence on them. In contrast, only about one-third of those interviewed from environmental groups or non-regulatory state and local government agencies described public participation as being directly connected to EM decisions; the remainder of these respondents saw the connection as being vague or uncertain or suggested that public participation had no appreciable effect on the decisions that were made. Environmental regulators were split approximately evenly between those who reported that public participation directly influenced EM decisions and those who saw any such influence as minimal. 



\section{CHAPTER 3. ATTRIBUTES OF SUCCESS}

The success of DOE's public participation efforts at its EM sites can be conceptualized in a number of different ways. For instance, one could say that a successful program is one that allows full and active stakeholder representation. One could also say that a successful program is one that results in the minimization of adverse environmental impacts, or one in which key decisions are accepted as legitimate by stakeholders. Each of these statements describes a specific attribute of success, focusing on a particular facet or characteristic of successful public participation programs. These statements could also be referred to as "conceptualizations" or "definitions" of success, but we prefer the term "attribute" because it conveys the idea that we are describing individual aspects of success, none of which-by itself-definitively describes program success. And using the term "attribute". helps emphasize that the various concepts of success presented here are not mutually exclusive. This chapter describes the 16 different attributes of success that were rated by our survey respondents, discusses what the respondents told us about each one, suggests a few other possible attributes, and-based on the survey results and our own analysis-suggests which attributes are most suitable for use in future evaluations.

\section{DESCRIPTION OF ATTRIBUTES RATED BY STAKEHOLDERS}

We asked survey respondents to rate 16 different attributes on the basis of how important they believed each one to be for evaluating the success of the public participation programs with which they had been involved. Then, in a follow-up question, we asked each respondent to list the five attributes that they considered most important for evaluating DOE's public participation efforts. Table 3.1 shows the attributes of success that we used in the survey, grouped into five broad subject areas: (1) the decision-making process; (2) effects of public participation on stakeholder understanding and attitudes; (3) effects of public participation on environmental management decisions; (4) effects of environmental management decisions on site conditions; and (5) effects of environmental management decisions on stakeholders' objectives. We believe that, between them, the set of 16 attributes covers all major stakeholder perspectives and provides a reasonably thorough listing of the ways in which success can be conceptualized for DOE's public participation efforts. Further, each attribute is broad enough to be useful in evaluating a wide range of public participation efforts focusing on a variety of environmental management programs.

\section{Attributes of Success that Focus on the Decision-making Process}

The decision-making process allows full and active stakeholder representation. This attribute addresses the opportunities that various interested parties have to present their views to DOE. This is an important component of what is sometimes referred to as "procedural justice," because it deals with how open or "accessible" the process is to the full range of participants. However, as with the previous attribute, this does not indicate how seriously DOE decisionmakers treat the input they receive from various stakeholders nor how much effect this input has on the decisions that are ultimately reached.

$D O E$ is presented with comprehensive and thoughtful input by the public. This attribute focuses on how successful federal decision-makers are in eliciting a full range of important information from all other stakeholders. However, this attribute does not address the issue of how seriously public input is treated nor its effect on subsequent decisions. 
Table 3.1. Attributes of success rated by survey respondents

\section{The Decision-Making Process}

- The decision-making process allows full and active stakeholder representation.

- DOE is presented with comprehensive and thoughtful input by the public.

- The decision-making process is accepted as legitimate by stakeholders.

\section{Effects of Public Participation on Stakeholder Understanding and Attitudes}

- The public understands DOE's environmental management problems and associated actions.

- The public understands the connection between clean-up costs and environmental benefits.

- DOE understands public concerns.

- The public has trust and confidence in DOE and the DOE facility.

III. Effects of Public Participation on Environmental Management Decisions

- Key decisions are influenced by the public.

- Key decisions are improved by public participation.

- Key decisions are accepted as legitimate by stakeholders.

\section{Effects of Environmental Management Decisions on Site Conditions}

- Environmental management costs are minimized.

- Adverse environmental impacts are minimized.

- Adverse impacts are distributed equitably among the public.

\section{Effects of Environmental Management Decisions on Stakeholders' Objectives}

- Stakeholder (DOE and non-DOE) objectives for a particular public participation effort are met.

- DOE's site-specific mission is accomplished.

- The overall objectives of non-DOE stakeholders are met.

The decision-making process is accepted as legitimate by stakeholders. This attribute describes the judgment of the various interested parties as to the fairness of the procedures by which key decisions are made. This attribute goes beyond the involvement of the various stakeholder groups to examine the acceptability of the entire decision-making process.

\section{Attributes of Success that Focus on Effects of Public Participation on Stakeholder Understanding and Attitudes}

The public understands DOE's environmental management problems and associated actions. This attribute refers to how successful DOE is in imparting information about its environmental management situation and proposed responses to the other stakeholders. By itself, this attribute addresses the educational rather than the interactive success of public participation efforts. 
The public understands the connection between clean-up costs and environmental benefits. This is very similar to the preceding attribute of success, except that it captures how well the public is educated about the trade-offs that frequently must be made between clean-up costs and environmental quality, rather than about the overall EM program.

DOE understands public concerns. This attribute is the counterpart to those attributes of success that focus on how well the public understands DOE issues and concerns. It also is very similar to the first attribute in the preceding category, except that it goes beyond the mere receipt of stakeholder input to address the comprehension of that information.

The public has trust and confidence in DOE and the DOE facility. This attribute focuses on how much confidence the public has in DOE and the correctness of its actions, and often is thought of as being directly related to how much resistance DOE is likely to encounter in performing those tasks that are vital to its mission.

\section{Attributes of Success that Focus on Effects of Public Participation on Environmental Management Decisions}

Key decisions are influenced by the public. The focus of this attribute is on the effect of public input on DOE's decisions and associated actions.

Key decisions are improved by public participation. This takes the previous attribute and adds a value component. Now, it is no longer enough for the public to influence a decision, but that decision has to be influenced in a manner that is considered positive by the parties involved.

Key decisions are accepted as legitimate by stakeholders. This is very similar to the last attribute in the first general category, except that this one focuses on the substantive decisions themselves rather than on the process by which they are reached.

\section{Attributes of Success that Focus on Effects of Environmental Management Decisions on Site Conditions}

Environmental management costs are minimized. This attribute focuses on the costs of environmental clean-up-which is important to DOE project managers and other costconscious stakeholders-without examining how effective DOE's actions are or how appropriate the public considers them to be.

Adverse environmental impacts are minimized. This attribute is the mirror image of the attribute discussed above, in that it focuses on environmental quality without focusing on the associated costs.

Adverse impacts are distributed equitably among the public. This attribute frames success in terms of how the negative effects associated with environmental management efforts are spread throughout the impact region. This issue often is considered under the rubric of "environmental justice" and reflects a concern that adverse impacts not be disproportionately placed upon minority or low-income communities.

\section{Attributes of Success that Focus on Effects of Environmental Management Decisions on Stakeholders' Objectives}

Stakeholder objectives for a particular public participation effort are met. This focuses on what DOE and all other stakeholders hope to accomplish through their public participation, and gauges success in terms of how well these objectives are satisfied. 


\section{Performance Measures for Evaluating Public Participation Activities in DOE's Office of Environmental Management}

DOE's site-specific mission is accomplished. This attribute describes success in terms of the accomplishment of DOE's goals. While the previous attribute examines how well the goals for a specific public participation effort are met, this one focuses on DOE's mission for the site in question (e.g., the safe management of all on-site wastes) and how well that mission is served by the public participation efforts under study.

The overall objectives of non-DOE stakeholders are met. This is an analogue to the attribute discussed immediately above. In this case, however, the overall mission of the external stakeholders is being addressed rather than DOE's mission.

\section{STAKEHOLDER RESPONSES TO ATTRIBUTES}

All 106 individuals who completed the written survey were categorized according to their main organizational affiliation, as shown in Fig. 3.1. Representatives of non-regulatory state and local government agencies-composed of elected officials, paid staff, and appointed board members - accounted for just under one-fourth of all survey respondents. Nearly onefifth of those completing the survey were DOE contractors, and almost as many were employed directly by DOE. ${ }^{6}$ Almost one-eighth of the survey respondents were members of non-government environmental and health groups, and just under one of every ten people completing the survey was classified as a state or federal environmental regulator. One of every fifteen survey respondents represented business interests, such as local chambers of commerce. Substantially smaller numbers of respondents were classified as being primarily affiliated with one of the other stakeholder groups: civic organizations, nearby property owners with a direct financial stake in the outcomes of the EM effort, Indian tribal government, or other interested parties.

Written surveys were completed and returned by respondents at all nine study sites. The largest numbers of completed surveys came from the Oak Ridge and Fernald sites, while the New Jersey FUSRAP site, Sandia, and SLAC had the fewest respondents.

For all respondents completing the written survey, the mean ratings describing the perceived importance of each attribute for evaluating the success of DOE's public participation efforts are shown in Table 3.2. On the five-point scale that was used-with one being "not important" and five being "essential" - six items received a mean score of four ("very important") or greater. In descending order from highest mean rating to lowest, these are: (1) the decision-making process is accepted as legitimate by stakeholders; (2) DOE understands public concerns; (3) the decision-making process allows full and active stakeholder representation; (4) key decisions are accepted as legitimate by stakeholders; (5) the public has trust and confidence in DOE and the DOE facility; and (6) key decisions are improved by public participation. No attribute received a mean score of less than three ("moderately important"), but the two least-favored attributes were relatively close to that mark: environmental management costs are minimized; and any adverse impacts are distributed equitably among the public.

In addition to asking respondents to rate the importance of the various attributes of success, we also asked which five attributes they considered to be most important for evaluating DOE's public participation efforts. We attached great significance to this latter question, because it required stakeholders to weigh the relative merits of all 16 attributes and declare which were best. Figure 3.2 shows the percentage of all survey respondents who included

6 Of the DOE and DOE-affiliated respondents, $47.3 \%$ were primarily involved with public participation, $39.5 \%$ were project management staff, and the remaining $13.2 \%$ were heavily involved with both public participation and project management. 


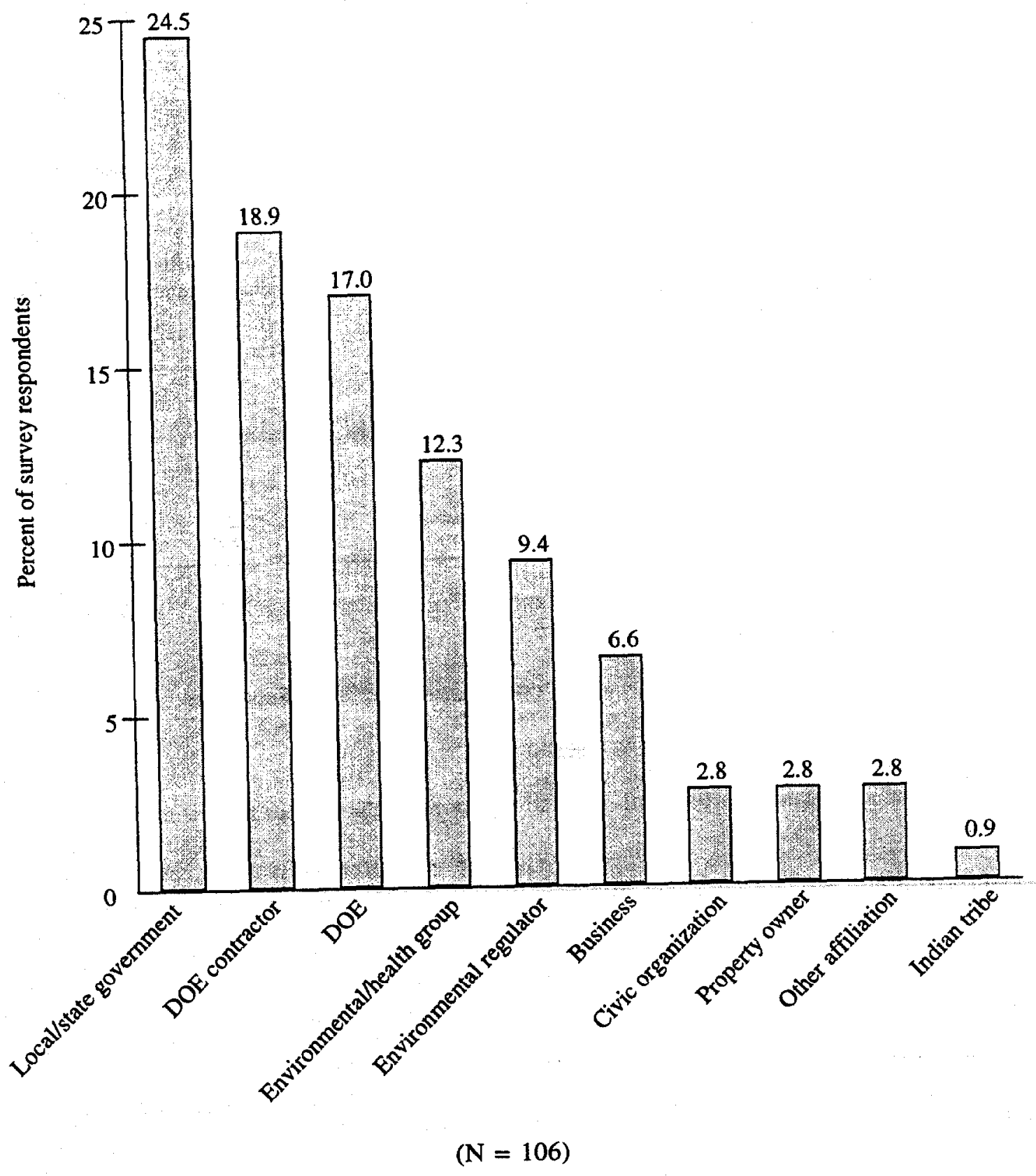

Fig. 3.1. Distribution of survey respondents, by organization type. 
Table 3.2 Mean rating for each attribute of success

\begin{tabular}{lc}
\multicolumn{1}{c}{ Attribute of Success } & $\begin{array}{c}\text { Mean } \\
\text { Rating }\end{array}$ \\
\hline & 4.46 \\
The decision-making process is accepted as legitimate by stakeholders & 4.35 \\
DOE understands public concerns & 4.31 \\
The decision-making process allows full and active stakeholder representation & 4.28 \\
Key decisions are accepted as legitimate by stakeholders & 4.15 \\
The public has trust and confidence in DOE and the DOE facility & 4.00 \\
Key decisions are improved by public participation & 3.90 \\
The public understands the connection between clean-up costs and environmental benefits & 3.88 \\
The public understands DOE's environmental management problems and associated actions & 3.85 \\
Key decisions are influenced by the public & 3.85 \\
Adverse environmental impacts are minimized & 3.80 \\
DOE is presented with comprehensive and thoughtful input by the public & 3.75 \\
DOE's site-specific mission is accomplished & 3.67 \\
Stakeholder (DOE and non-DOE) objectives for a particular public participation effort are met & 3.55 \\
The overall objectives of non-DOE stakeholders are met & 3.30 \\
Environmental management costs are minimized & 3.23 \\
Any adverse impacts are distributed equitably among the public &
\end{tabular}

each item in their list of the five most important attributes of success. Three attributes stood out as clearly more important than all the rest:

- the decision-making process is accepted as legitimate by stakeholders;

- DOE understands public concerns; and

- the decision-making process allows full and active stakeholder representation.

Each of these attributes was on the "top five" list for over three-fifths of all respondents. Not surprisingly, these are the same attributes identified above as receiving the three highest mean ratings on our five-point scale. Another block of three attributes-while not as widely mentioned as the first three-emerged as being very important to a substantial number of respondents. These attributes are: the public has trust and confidence in DOE and the DOE facility; key decisions are accepted as legitimate by stakeholders; and key decisions are improved by public participation. These attributes, which were on the "top five" lists for about two-fifths of all respondents, are the same as those receiving the fourth through sixth highest mean ratings on the previously mentioned scaled question concerning attribute importance.

Disaggregating survey results by organizational type is necessary to see if differences emerge among the different types of stakeholders in terms of the attributes that they favor. Table 3.3 shows which items most frequently appeared on the "top five" lists of the stakeholder groups with the greatest number of respondents. An examination of the table reveals that the top three attributes listed above were among the most frequently mentioned 


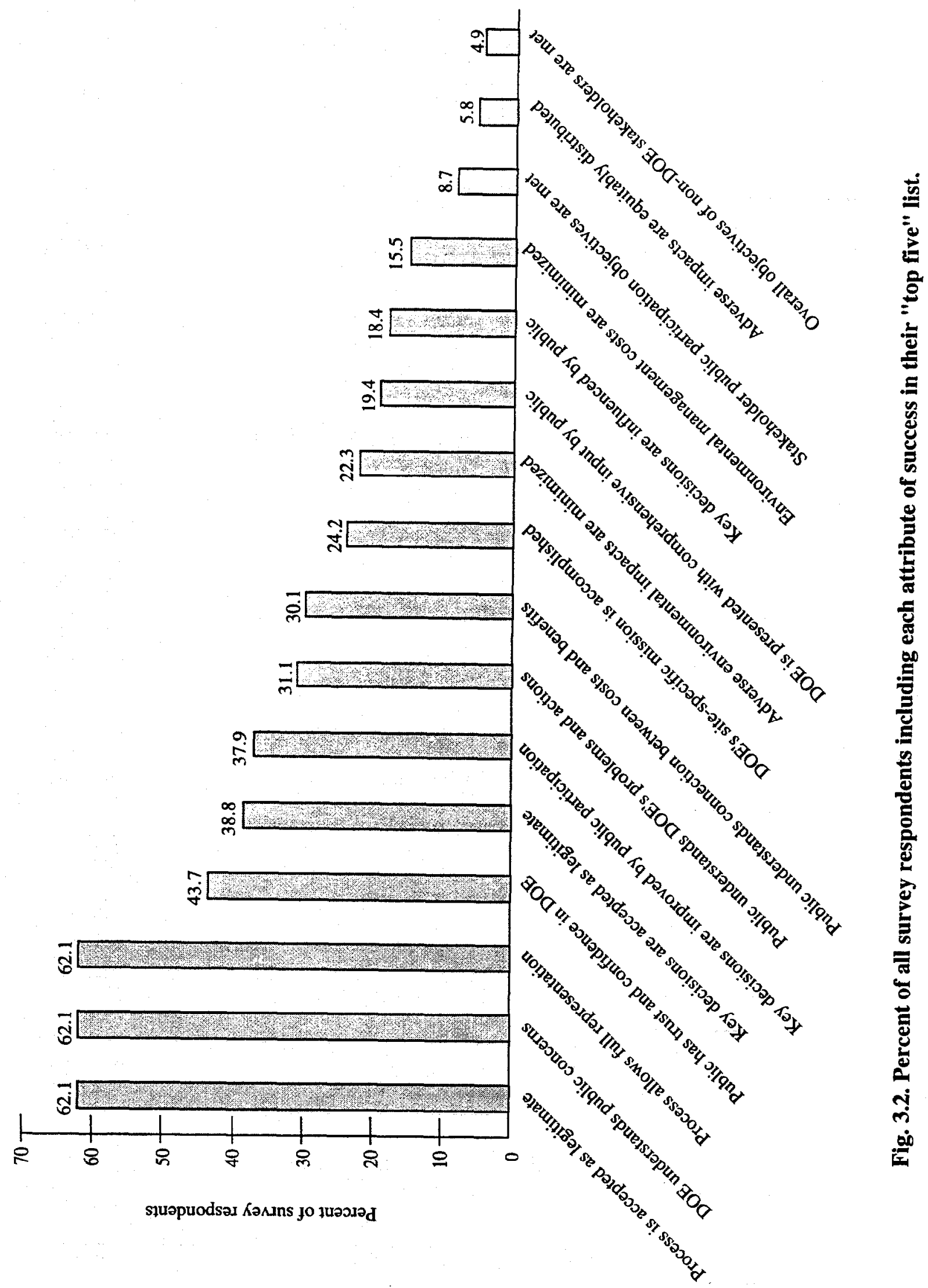


Table 3.3. Attributes of success appearing in respondents' "top five" lists most frequently, by organization type

\begin{tabular}{|c|c|c|}
\hline $\begin{array}{c}\text { Organization } \\
\text { type }\end{array}$ & Attribute of success & $\begin{array}{l}\text { Percent } \\
\text { (frequency) } \\
\text { of } \\
\text { respondents } \\
\text { including in } \\
\text { "top five" } \\
\text { list }\end{array}$ \\
\hline & $\cdots$ & \\
\hline $\begin{array}{l}\text { Local/state } \\
\text { government } \\
(\mathrm{N}=26)\end{array}$ & $\begin{array}{l}\text { DOE understands public concerns } \\
\text { The decision-making process allows full and active stakeholder representation } \\
\text { The decision-making process is accepted as legitimate by stakeholders } \\
\text { The public has trust and confidence in DOE and the DOE facility } \\
\text { Key decisions are improved by public participation }\end{array}$ & $\begin{array}{l}69.2(18) \\
65.4(17) \\
61.5(16) \\
50.0(13) \\
46.2(12)\end{array}$ \\
\hline $\begin{array}{l}\text { DOE } \\
\text { contractor } \\
(\mathrm{N}=20)\end{array}$ & $\begin{array}{l}\text { The decision-making process is accepted as legitimate by stakeholders } \\
\text { The decision-making process allows full and active stakeholder representation } \\
\text { The public has trust and confidence in DOE and the DOE facility } \\
\text { DOE understands public concerns } \\
\text { Key decisions are accepted as legitimate by stakeholders }\end{array}$ & $\begin{array}{l}80.0(16) \\
65.0(13) \\
50.0(10) \\
45.0(9) \\
40.0(8)\end{array}$ \\
\hline $\begin{array}{l}\text { DOE } \\
(\mathrm{N}=17)\end{array}$ & $\begin{array}{l}\text { DOE understands public concerns } \\
\text { The decision-making process is accepted as legitimate by stakeholders } \\
\text { DOE's site-specific mission is accomplished } \\
\text { Key decisions are improved by public participation } \\
\text { Key decisions are accepted as legitimate by stakeholders }\end{array}$ & $\begin{array}{l}82.4(14) \\
64.7(11) \\
52.9(9) \\
47.1(8) \\
41.2(7)\end{array}$ \\
\hline $\begin{array}{l}\text { Environmental/ } \\
\text { health group } \\
(\mathrm{N}=11)\end{array}$ & $\begin{array}{l}\text { The decision-making process allows full and active stakeholder representation } \\
\text { DOE understands public concerns } \\
\text { The public understands DOE's environmental management problems and } \\
\text { associated actions } \\
\text { The decision-making process is accepted as legitimate by stakeholders } \\
\text { DOE is presented with comprehensive and thoughtful input by the public }\end{array}$ & $\begin{array}{l}81.8(9) \\
72.7(8) \\
54.5(6) \\
45.5(5) \\
45.5(5)\end{array}$ \\
\hline $\begin{array}{l}\text { Environmental } \\
\text { regulator } \\
(\mathrm{N}=10)\end{array}$ & $\begin{array}{l}\text { The decision-making process is accepted as legitimate by stakeholders } \\
\text { DOE understands public concerns } \\
\text { The decision-making process allows full and active stakeholder representation } \\
\text { Key decisions are accepted as legitimate by stakeholders } \\
\text { The public has trust and confidence in DOE and the DOE facility }\end{array}$ & $\begin{array}{l}80.0(8) \\
70.0(7) \\
60.0(6) \\
60.0(6) \\
50.0(5)\end{array}$ \\
\hline $\begin{array}{l}\text { Business }{ }^{a} \\
(\mathrm{~N}=7)\end{array}$ & $\begin{array}{l}\text { The decision-making process allows full and active stakeholder representation } \\
\text { Key decisions are improved by public participation } \\
\text { Key decisions are accepted as legitimate by stakeholders } \\
\text { The decision-making process is accepted as legitimate by stakeholders } \\
\text { The public has trust and confidence in DOE and the DOE facility } \\
\text { The public understands the connection between clean-up costs and } \\
\text { environmental benefits } \\
\text { DOE's site-specific mission is accomplished }\end{array}$ & $\begin{array}{l}85.7(6) \\
57.1(4) \\
57.1(4) \\
42.9(3) \\
42.9(3) \\
42.9(3) \\
42.9(3)\end{array}$ \\
\hline
\end{tabular}

\footnotetext{
a More than five attributes are listed for this organization type due to ties among the "bottom" four attributes.
} 
items in the "top five" lists for nearly every type of organization represented. In addition, these three attributes were the only ones that were on the "top five" lists of more than $60 \%$ of the respondents in any stakeholder category. "The decision-making process is accepted as legitimate by stakeholders" was among the five most frequently mentioned "top five" items for all organization types, and was among the three most often listed for all except environmental/health groups and business organizations. "DOE understands public concerns" was among the five most frequently mentioned items for all groups except for business organizations, and among the top two for everyone except DOE contractors and business groups. And "the decision-making process allows full and active stakeholder representation" was among the three most frequently mentioned items for all groups except DOE.

The next two most popular attributes also did well with most organization types, but there was not the unanimity, or near-unanimity, of opinion that we found for the first three items. "The public has trust and confidence in DOE and the DOE facility" was among the five attributes that appeared most frequently on respondents' "top five" lists for all except DOE and environmental/health organizations. For all stakeholder groups except state/local government and environmental/health groups, "key decisions are accepted as legitimate by stakeholders" was among the five most frequently mentioned "top five" items; this item was especially popular among environmental regulators and business interests. And "key decisions are improved by public participation" was among the five attributes appearing most frequently on the "top five" lists of half of the most common stakeholder groups: business (with whom it was particularly popular), state/local government, and DOE.

A few other attributes frequently appeared on the "top five" lists for one or two stakeholder groups. Most notably, "DOE's site-specific mission is accomplished" was among the most frequently mentioned "top five" items for DOE and business groups. For environmental/ health groups, "the public understands DOE's environmental management problems and associated actions" was among the three attributes appearing most frequently on respondents' "top five" lists.

When disaggregating the survey responses by site, we find that the three most popular attributes described above were also among the five items appearing most frequently on the "top five" lists of virtually every site. ${ }^{7}$ The three next most popular attributes also were among the most frequently listed "top five" items for many of the sites. In addition, "the public understands DOE's environmental management problems and associated actions", which was highly rated by environmental/health groups, was among the most frequently mentioned "top five" items at five of the nine study sites.

\section{OTHER POSSIBLE ATTRIBUTES}

In addition to asking respondents to rate the importance of 16 different attributes of success, the written survey also provided the opportunity to suggest "other" attributes. Of the 106 individuals who completed the survey, 17 described other attributes of success. We believe that most of these other attributes were quite similar to the attributes listed in the survey, differing in wording or emphasis but not in concept. Three of the suggested attributes, however, were sufficiently different from the other 16 to warrant further consideration. In addition, a fourth new attribute was suggested by our ongoing literature review and was also examined. These four "other" attributes are: "the public is presented

7 "The decision-making process allows full and active stakeholder representation" is the only one of the three attributes that was not among the most frequently listed "top five" items at every site, and this was only missing at a single location. 


\section{Performance Measures for Evaluating Public Participation Activities in DOE's Office of Environmental Management}

with comprehensive information by DOE"; "various stakeholders understand one another's concerns"; "DOE and the public understand the long-term environmental consequences of the decision"; and "existing conflicts are resolved." Each is discussed briefly below.

"The public is presented with comprehensive information by DOE" is an analogue to an attribute that appeared in the survey: "DOE is presented with comprehensive and thoughtful input by the public". That survey item was given relatively low ratings by most respondents, indicating that the provision of information is less important to stakeholders than are other attributes. Also, because this new attribute falls under the general category of "the decision-making process" and that category is well-represented by two top-ranking attributes, it is unlikely that this new item would contribute significantly to our understanding of public participation success.

"Various stakeholders understand one another's concerns" is basically a combination of two existing attributes: "the public understands DOE's environmental management problems and associated actions" and "DOE understands public concerns." This new attribute, therefore, could substitute for two well-received attributes and adds the conceptpreviously not addressed - of different internal and external stakeholders understanding each other.

"DOE and the public understand the long-term environmental consequences of the decision" is similar, but not identical, to "the public understands the connection between clean-up costs and environmental benefits." It also covers much the same subject matter as another attribute: "adverse environmental impacts are minimized." Neither of these attributes was highly favored by survey respondents. Finally, this suggested attribute is also related to the survey attributes dealing with understanding by DOE and the public of each others' concerns, problems, and activities, at least to the extent that DOE and its stakeholders have expressed their concerns related to long-term environmental consequences. We conclude that the use of this new attribute is unlikely to address the central concerns of the interested parties that are not already addressed by attributes listed in the survey.

The last new attribute is "existing conflicts are resolved." While not identical, this attribute covers much the same ground as "the public has trust and confidence in DOE and the DOE facility," since the development of trust and confidence is likely to be accompanied by an easing of conflict. However, the value of conflict resolution by itself can be difficult to interpret. In addition to indicating public satisfaction, the cessation of conflict could also mean that external stakeholders are unhappy but resigned and have given up trying to influence DOE, or that they are pursuing alternative approaches to influencing DOE's actions.

\section{KEY ATTRIBUTES TO USE IN FUTURE EVALUATIONS}

Based on the information and analysis presented in the preceding sections, we suggest the use of seven attributes of success in future evaluations of DOE's public participation programs: (1) the decision-making process allows full and active stakeholder representation; (2) the decision-making process is accepted as legitimate by stakeholders; (3) DOE and other stakeholders understand each others' concerns; (4) the public has trust and confidence in DOE and the DOE facility; (5) key decisions are improved by public participation; (6) key decisions are accepted as legitimate by stakeholders; and (7) DOE's site-specific mission is accomplished. As shown in Table 3.4, the first two of these attributes fall under the category of the decision-making process, the next two address effects of public participation on stakeholder understanding and attitudes, the following two deal with effects of public participation on environmental management decisions, and the last one concerns effects of environmental 
Table 3.4. Key attributes of success to use in future evaluation

The decision-making process

- The decision-making process allows full and active stakeholder representation

- The decision-making process is accepted as legitimate by stakeholders

Effects of public participation on stakeholder understanding and attitudes

- DOE and other stakeholders understand each others' concerns

- The public has trust and confidence in DOE and the DOE facility

Effects of public participation on Environmental Management decisions

- Key decisions are improved by public participation

- Key decisions are accepted as legitimate by stakeholders

Effects of Environmental Management decisions on stakeholders' objectives

- DOE's site-specific mission is accomplished

management decisions on stakeholders' objectives. In line with the input provided by a broad range of stakeholder groups, our collection of suggested attributes places more emphasis on process, understanding, and decisions than on directly measuring the effects of the decisions that are made. Apparently, most respondents believe that if the process is fair, if understanding and trust are enhanced, and if good decisions are reached, then the ultimate effects of the decisions will be acceptable.

Nearly all of the attributes suggested here were considered very important by most stakeholder groups, and any attribute that was unimportant to a given group tends to be balanced by one or more attributes that were highly relevant to that same group. The only attribute in our final list that was not broadly embraced by survey respondents is the last item ${ }^{8}$ : "DOE's site-specific mission is accomplished." However, many respondents did note that stakeholders needed to be involved actively in developing mission statements. Moreover, we believe that this attribute is essential because DOE, as the agency sponsoring the public participation efforts in question, needs to know how these programs affect its underlying mission. In addition, evaluating the extent to which DOE's site-specific mission has been accomplished lends itself to the use of performance indicators that examine how site conditions (e.g., environmental management costs, adverse environmental impacts, and the distribution of those impacts) have been affected-a topic that is not broached by any of the other attributes that we suggest. In fact, as shown in the next chapter, many of the performance indicators suggested by respondents for this attribute specifically mention changes in site conditions (including remediation and/or containment costs and

\footnotetext{
8 Although one of our suggested attributes-'DOE and other stakeholders understand each others' concerns"-was not directly considered by survey respondents, it is a combination of two attributes that were highly regarded by a broad range of stakeholders.
} 
environmental conditions) as appropriate indicators for accomplishment of the site-specific mission.

In addition to addressing the concerns of a broad range of stakeholders, the combined sct of attributes that we are suggesting is appropriate for describing what was accomplished at all of our study sites, despite the fact that there was substantial variation among them in the scope and timing of their environmental management activities. Sites that are not as far along as others in terms of their EM activities will yield less definitive results when measuring the attributes concerning decisions and objectives, but the inclusion of numerous attributes addressing the decision-making process and stakeholder understanding assures that a meaningful evaluation will still be possible. Because of its good fit with our nine study sites, we believe that our suggested set of seven attributes will be appropriate for evaluating the large majority of EM sites around the country. Of course, in the event that unusual site conditions or stakeholder concerns make one or more of the seven attributes inappropriate or suggest that other attributes might be more useful, individual evaluators could choose their own combination of attributes, selecting from the full set discussed earlier in this Chapter.

When performing an evaluation of a particular public participation effort, we believe that each of the attributes discussed above should be considered separately, rather than weighting them to come up with a single tally of success. Not only is it extremely difficult to come up with a widely acceptable weighting system that is meaningful for all interested parties, but focusing on a single "success score" rather than on multiple attributes of success obscures the rich descriptiveness of what was accomplished according to various perspectives. Moreover, a single score can be very misleading.

In the next chapter, we suggest performance indicators that can be employed to measure program performance according to each of our seven attributes of success. 


\section{CHAPTER 4. PERFORMANCE INDICATORS}

Performance indicators are measurable (i.e., quantifiable) factors that can be used to gauge the extent to which a particular public participation program or activity has been successful according to a given attribute of success. Indicators can be developed to measure actual behavior, events, and actions as well as perceptions to determine the extent to which an effort was successful according to a specific attribute of success. Quantitative findings may have greater accuracy and credibility than non-quantitative indicators, at least among some stakeholders and some auditing- or oversight-type organizations (e.g., programs offices, Congress, and the Office of Management and Budget) because of their potential for comparative analysis. For some projects, programs, or activities, where it is understood that the total process may take several years (or more) to complete the action, "final" data may not be readily available until a particular clean-up, remediation, or waste management action is completed. On the other hand, interim or preliminary data may be developed based on predictive preliminary investigations, including items such as engineering cost analyses or environmental impact assessments of alternative decisions, including those "selected" or "modified" by public participation.

Some indicators, particularly those measuring perceptions or attitudes, may be of substantial value in trending analyses. If one rating can be compared to other earlier ratings, it is possible to determine whether public involvement activities are helping or hurting things according to the attribute in question.

Most of the 16 attributes of success discussed in Chapter 3 can be measured reasonably well by both indicators associated with actual behavior or perceptions. In a few cases, however, only perceptual or behavioral indicators are likely to be appropriate or yield the most relevant information. When in doubt, or under some other conditions, an evaluator could use both perceptual and behavioral indicators for a single attribute. Examples of both types of indicators are presented in the following discussion of performance indicators for use in future evaluations.

The performance indicators we identify and discuss below were developed using a number of sources and methods. We conducted reviews of appropriate research and practitioner literatures [i.e., dealing with public and stakeholder participation (e.g., Kraft 1988, Hutcheson and Shevin 1976, Alinsky 1946, Arnstein 1969, Milbrath 1981, and Lowi, Ginsberg, et al. 1976 ), bureaucratic systems (e.g., Yates 1982, Baumgartner and Jones 1993, Bosso 1994, Rochefort and Cobb 1994, and Hilgartner and Bosk 1988), democratic theory and theories of justice (e.g., Tyler 1990, Fisher and Ury 1983, Lindblom 1990, Schattschneider 1960, Shklar 1990, and Mansbridge 1990), program evaluation research (e.g., Lach, Hixson, and Ramonas 1995, MaGuire 1995, Young, Williams, and Goldberg 1993, Syme and Sadler 1994, and Roesener 1978), and policy implementation (e.g., Pressman and Wildavsky 1973 and Bardach 1977)],

Our most important sources of information in developing performance indicators for the selected attributes, however, were the stakeholders themselves. As indicated earlier, both our field and telephone interviews, as well as the surveys returned by the respondents from the nine EM sites, provided much information and insight into how different attributes of success might be measured. With respect to the survey instrument, we asked stakeholders to suggest performance measures for a few specified attributes as well as for the five attributes they considered to be most important. We then collected the performance indicators suggested by respondents for each of the attributes that we consider most important (see Chapter 3), looking for dominant themes and common performance indicators identified by different kinds of stakeholders at the various EM sites. 
In the remainder of this chapter, we discuss a number of possible performance indicators for each of the seven attributes identified in Chapter 3 as most suitable for future evaluations and recommend the most suitable perceptual or bchavioral indicator(s) to use with each attribute. Our recommendations are based on: (1) the suggestions of stakeholders; (2) our attempt to compile, contrast, coordinate, and combine those suggestions, where appropriate; and (3) our judgment, based on the data, appropriate prior research, and our professional experience, regarding how best to word particular performance indicators so that they are useful in a variety of EM contexts (e.g., how best to accommodate project- or site-specific variation throughout the EM complex).

\section{THE DECISION-MAKING PROCESS ALLOWS FULL AND ACTIVE STAKEHOLDER REPRESENTATION}

Approximately one-fifth of all respondents offered suggestions regarding how this attribute might be measured. These suggestions varied somewhat according to the types of public and stakeholder involvement opportunities utilized for a given project, particularly in terms of whether full and relatively infrequent public meetings and hearings were used as the major source of stakeholder input to DOE, as contrasted with working groups and other mechanisms offering more frequent interactions between the public and DOE.

The respondents identified both behavioral and perceptual performance indicators that could be used to measure success for this attribute. Behavioral indicators included issues such as: (1) the retention of public and stakeholder interest and participation over the life of the project or program; (2) the diversity of public participation (e.g., the fraction of local groups represented in any public participation process); (3) the announcement and implementation of diverse participation mechanisms that might appeal to different members of the public (e.g., public meetings, facility tours, newsletters, availability of site and project management and project technical staff to answer questions, speakers' bureau for interested groups, stakeholder workshops, and project working groups to deal directly with DOE regarding the project or program and associated "technical" and policy decisions); and (4) the use of specific and diverse processes or mechanisms to notify stakeholder groups about public participation opportunities.

There were many fewer suggestions from survey respondents for perceptual indicators of this attribute. Basically, the suggestions involved implementing surveys of stakeholder participants (and possibly non-participants) to determine whether they were satisfied with the comprehensiveness of public participation in a given project and the public participation process in general, and to explore stakeholder understanding of the decision-making process. The second part of this proposed survey actually addresses a different attribute (see below).

Given the preponderance of behavioral indicators recommended by stakeholders and because the components of full representation lend themselves to such measurement, we recommend the use of behavioral performance indicators for this attribute. These indicators should focus on the breadth of stakeholder groups involved and on the public participation opportunities afforded all interested parties. Specifically, we recommend measuring success in terms of the following:

- The proportion of all identifiable stakeholder groups that have taken part in public participation efforts; and

- The mechanisms used to attract, engage, and maintain the interest of stakeholders throughout the public participation effort. 


\section{THE DECISION-MAKING PROCESS IS ACCEPTED AS LEGITIMATE BY STAKEHOLDERS}

Approximately 30 percent of all respondents offered suggestions regarding how this attribute might be measured. These suggestions varied somewhat according to the different stages or decision points of an activity, project, or program [e.g., problem definition, mission statement development, data collection and analysis to evaluate reasonable alternatives, development of a decision, permitting, and implementation of the decision].

The respondents identified both behavioral and perceptual performance indicators for this attribute. Behavioral indicators included: (1) amount of opposition to implementation of the decision, as manifested by letters to the local print media for supporting or opposing the EM activity in question; (2) public support by participating groups for the findings resulting from their activity; (3) actual use by DOE of public input in developing alternatives and the decision; (4) documented responsiveness of DOE to public and stakeholder comments and suggestions; and (5) actual stakeholder participation in decision-making.

There were somewhat fewer suggestions from survey respondents for perceptual indicators of this attribute. Basically, the suggestions focused on the techniques that could be used (e.g., focus groups, surveys) to determine whether the public understood the decisionmaking process and believed the decision-making process was legitimate, whether they agreed with the decision or not.

We can imagine the use of certain behavioral indicators (such as those described above) to measure the degree to which the public believes that the decision-making process is legitimate. However, given the inherently perceptual nature of legitimacy, which is similar to other umbrella-type terms like trust and confidence, it seems that more meaningful and accurate results would be obtained by directly asking participating stakeholders for their direct appraisal of the legitimacy of the decision-making process. Specifically, we recommend the use of the following perceptual indicator:

- Participants' evaluation of the legitimacy of decision-making processes at various stages in the decisions cycle for the EM activity in question.

\section{DOE AND OTHER STAKEHOLDERS UNDERSTAND EACH OTHERS' CONCERNS}

Approximately 25 percent of all respondents offered suggestions regarding how this attribute might be measured. The suggestions focused on several different dimensions: whether DOE and its contractor understand stakeholder concerns as compared to stakeholder understanding of DOE concerns; whether the indicator could be measured "independently" by DOE and its contractor (e.g., by tracking DOE/contractor responsiveness to every comment provided by the public); how the mutual understanding implicit in this attribute could be measured; and whether there was full understanding, by all parties, of the balance between the cost and benefits of alternative EM decisions.

Although it is possible to identify perceptual indicators of mutual understanding (e.g., use of a survey asking respondents whether they understand others' concerns), virtually all of the performance indicators suggested by the respondents were behavioral in nature.

Behavioral indicators included issues such as: (1) the treatment and disposition of stakeholder concerns by DOE and its contractor(s); (2) the preparation of a report or planning document, at appropriate stages of the project or program, identifying stakeholder concerns and DOE responses to those concerns; (3) the regularity of updates and briefings provided by DOE/ 


\section{Performance Measures for Evaluating Public Participation Activities in DOE's Office of Environmental Management}

contractor(s) to the public; (4) the understandability of project/program literature to the public; (5) the accuracy of electronic and print media reports and "letters to the editor" with regard to facts surrounding the project, program, or site; (6) the ratio of the number of comments and statements from external stakeholders reflecting understanding as compared to ignorance or confusion; (7) the behavior of internal and external stakeholders at open meetings (e.g., evidence of concern, openness, positiveness, and caring); and (8) the ability of internal and external stakeholders to identify each others' concerns and constraints, understand the bases of those concerns and constraints, and demonstrate respect for one another.

In addition to these behavioral measures, several respondents specifically addressed understanding of the balance between waste management/restoration costs and benefits. The suggestions on measuring mutual understanding of this particular issue were both behavioral and perceptual - a behavioral measure might include tracking the changing ratio of project or program cost to appropriate measures of cleanup or management (e.g., acres remediated, quantity of wastes managed or disposed), and perceptual measures could include surveying the public and stakeholders regarding their understanding of the connection between financial costs and level of cleanup.

We agree with the respondents' view that behavioral indicators are most appropriate to measure the level of mutual understanding. Although many, if not most, of those suggested by respondents could be suitable for developing a specific indicator, our judgment is that some of the indicators mentioned by respondents appear to focus mostly on sequential, and perhaps formal, stages of one-way communications (i.e., external stakeholders express concerns to DOE and its contractor, followed by DOE and contractor responses to the stakeholders and their expressed concerns, or the reverse of this sequence). This concept of mutual understanding, although valid and certainly preferred over the historically more traditional concept of one-way communication (i.e., no dialogue whatsoever), does not take advantage of the opportunities for mutual learning obtained through informal, as well as formal, interactions between internal and external stakeholders. The suggested performance indicator for this attribute measures how formal and informal interactions have affected all participants' understanding of each others' concerns in the following way:

- Internal and external stakeholders' ability to identify each others' concerns and understand the bases of those concerns.

\section{THE PUBLIC HAS TRUST AND CONFIDENCE IN DOE AND THE DOE FACILITY}

Approximately 20 percent of all respondents offered suggestions regarding how this attribute might be measured. A greater proportion of the respondents might have offered suggestions had many of them not already been familiar with DOE's existing trust and confidence survey.

About half of the respondents who suggested performance indicators for this attribute favored the use of behavioral measures. Some believed that achievement of trust and confidence could be measured by the appearance of what might be considered normalcy, or the absence of conflict in the life of an EM project or program. Suggestions for how this attribute could be measured include the degree to which attendance and behavior at public meetings appear to be without rancor, the degree to which external stakeholders accept DOE's information and its responses to their comments and questions without having to resort to outside expertise, and the existence of balanced media coverage. In short, there is an appearance in the community of accomplishment, and both the public and DOE are pleased 
with the decision-making and public participation processes and outcomes. There were also some respondents who thought that the development of trust and confidence should be measured by a higher degree of outward support for whatever decision might be made and implemented. This support could be measured by the expression of public support by working groups, citizen advisory boards, regulators, and other stakeholders. There might even be an accelerated decision schedule, flexible reciprocity among internal and external stakeholders, an absence of litigation and acrimony leading to litigation, and the acceptance of new methods.

An equal segment of the respondents favored the use of surveys and/or focus groups to ask the public its perceptions regarding trust and confidence in DOE generally, the particular DOE site, and/or the particular EM activity, project, or program. As mentioned earlier, there may have been other respondents who did not explicitly offer a suggestion regarding how to measure this attribute who assumed that trust and confidence would be measured as is currently done in the EM trust and confidence survey.

Some respondents suggested the kinds of actions that DOE might take to enhance trust and confidence, such as maintaining open lines of communication, answering questions in a timely fashion, and accepting criticism and responding to such in a professional manner. Although these are certainly important ingredients in DOE enhancing public trust and confidence in DOE, they do not seem to be appropriate measures of trust and confidence at any given time.

We can imagine the use of certain behavioral indicators (such as those described above) to measure the degree to which external stakeholders have trust and confidence in DOE and the DOE facility. However, given the inherently perceptual nature of trust and confidence and the significant variability in how different people may define this concept, it seems that more meaningful and accurate results may be obtained by directly asking the public for their responses to this attribute. Accordingly, we recommend the use of the following subjective indicator, as applied to a specific EM project, site, or program:

- The public's self-reported levels of trust and confidence in DOE and its contractors.

\section{KEY DECISIONS ARE IMPROVED BY PUBLIC PARTICIPATION}

Approximately 10 percent of all respondents offered suggestions regarding how this attribute might be measured. These suggestions included both behavioral and perceptual performance measures. The suggested behavioral measures included documentation of (1) changes made in decision documents as a result of stakeholder involvement; (2) cost savings, volume reduction, schedule improvement, decrease in contamination, or whatever other benefit was gained through public participation; (3) improvement in cost/benefit ratio attributed to public involvement; (4) enhanced agreement between internal and external stakeholders regarding preferred remediation or waste management alternatives resulting from public participation; and (5) improvement of scientific or engineering validity with stakeholder involvement. ${ }^{9}$

The perceptual measures suggested by respondents focused on the extent to which DOE has considered concerns identified by external stakeholders in its decision-making. The presumption here is that different members of the stakeholder groups vary with respect to their characterization of what would constitute an improvement in key EM decisions.

${ }^{9}$ A couple of respondents also suggested reductions in the number of negative media reports or the number of lawsuits filed, but these measures appear to fit better with mutual understanding or perceived legitimacy of the decision. 
Although the behavioral measures suggested by respondents are, in some ways, compelling, they are difficult to measure until the entire project and all associated public participation activities have been completed. At that time, the improvement of the key decisions resulting from public involvement would be interesting, particularly in a research context, but may add little to the ability of DOE and all its stakeholders to enhance the development of improved decisions. Perceptual measures, on the other hand, may be more effective as formative performance indicators (i.e., mid-course indicators) that could facilitate the development of improved decisions throughout the life of the EM activity, project, or program. We suggest that periodic measurement of the improvement of key decisions due to public involvement during the decision-making process can improve the decisions that are made, whereas the use of behavioral measures may be of less use during the activity or program but of some use at the end of the decision process. It would be possible to measure whether decisions had been changed as a result of public participation (i.e., as a specific action taken or not taken by DOE), but the concept of improvement is, at this time, very perceptual and suggests the need to ask participants for their judgment or perceptions on whether (and how much) public participation has led to better decisions. For these reasons, we suggest use of the following perceptual indicator for this attribute:

- Judgments by internal and external stakeholders that public participation has led to better decisions.

\section{KEY DECISIONS ARE ACCEPTED AS LEGITIMATE BY STAKEHOLDERS}

Approximately 10 percent of all respondents offered suggestions regarding how this attribute might be measured. As was the case for the legitimacy of the decision-making process, these suggestions varied somewhat according to the decision points of an activity, project, or program. Many of the suggested performance measures for this attribute paralleled those suggested for measuring the legitimacy of the decision-making process, with a simple shift in focus from the legitimacy or fairness of the process (i.e., procedural justice) to the legitimacy or fairness of the decision itself (i.e., distributive justice).

The respondents identified both behavioral and perceptual performance indicators for this attribute. Behavioral indicators included issues such as: (1) demonstrated support for a decision by the public at post-decision public meetings (e.g., participating stakeholder group(s) publicly support the decision and associated permitting activities); (2) demonstrated opposition to a decision by the public after the decision is made (e.g., letters to the local print media opposing the EM decision and any litigation addressing the EM decision); and (3) documentation of post-decision support for a decision by DOE and its regulators (i.e., EPA, other federal agencies, and state/local regulators).

There were somewhat fewer suggestions from survey respondents for perceptual indicators of this attribute. Once again, the suggestions focused on the techniques that could be used to determine whether the stakeholders believed that the decision was legitimate or fair, regardless of whether they agreed with the decision-making process or not.

We can imagine the use of certain behavioral indicators (such as those described above) to measure the degree to which the public believes that the decision is legitimate. However, as was true for the legitimacy of the decision-making process, it seems that more meaningful and useful results would be obtained by directly asking internal and external stakeholders for their judgment concerning the legitimacy of the decisions that have been made. Accordingly, we recommend that the following perceptual indicator be used:

- Participants' evaluation of the legitimacy of decisions for a given EM activity. 


\section{DOE's SITE-SPECIFIC MISSION IS ACCOMPLISHED}

Approximately 30 percent of all respondents offered suggestions regarding how this attribute, in combination with other relevant attributes, might be measured. ${ }^{10}$ As noted in Chapter 3, a major comment from many respondents regarding this attribute, and any associated performance measures, concerned the importance of a clearly defined mission, preferably developed in concert with and through public participation. In fact, some respondents believed that if the site- or EM activity-specific mission was clearly defined, measuring the extent to which that mission was accomplished could be relatively straightforward.

The specific suggestions regarding this attribute included both behavioral and perceptual measures. The suggestions for behavioral indicators included: (1) public awareness and acceptance (or rejection) of the EM activity's mission, elements, and planned accomplishments; (2) levels of cleanup or waste management achieved with the EM activity [e.g., acres remediated; waste managed or disposed of; acres returned to public use; levels of contaminants removed; number of sites remediated; number of curies of waste treated, shipped, or disposed; amount of waste stabilized; improved safety record (for the public, workers, and the environment); accident/incident history; and amount of contamination no longer leaving the project or site]; (3) decreases in violations of air and water quality and other permits; (4) documentation of cost, expressed as remediation or management efficiency (e.g., cost per cubic yard of waste disposed or ton of hazardous waste treated), and possibly compared to similar achievements in the private sector and abroad; (5) documentation of cost reductions for mission accomplishment under the selected approach or technology as compared with various other viable alternatives; (6) maintenance of project schedules; and (7) the spatial and temporal distribution of existing and post-activity health, safety, and environmental impacts (to determine if they are distributed equitably among the public).

There were far fewer suggestions from the respondents regarding perceptual indicators to measure this attribute. As with previous perceptual indicators, respondents' suggestions focused on the development and implementation of techniques that could be used to determine whether stakeholders believed DOE had accomplished its mission. Specific suggestions included the use of follow-up surveys, opinion polls, interviews, and/or expert evaluations addressing the overriding public view of DOE and its work.

While it is true that interested parties could offer their opinions on how clean-up costs, environmental impacts, and management of the activity were affected by the public participation effort, behavioral indicators to address these topics are likely to provide a more definitive account than would perceptual impressions. It should be noted that the data necessary to measure some of these behavioral indicators definitively are likely to be available only upon completion of the environmental clean-up or waste management effort, and even then extensive auditing (e.g., environmental, health, financial) may be required to develop values accepted as valid by the diversity of local, state, tribal, and federal stakeholders. For this reason, when an objective indicator is modified for site- or activity-specific use, it is important to incorporate the concerns of all stakeholders in all relevant jurisdictions.

\footnotetext{
${ }^{10}$ Many respondents identified cost and environmental impact minimization and the equitable distribution of those impacts in response to this mission-oriented attribute, even though these indicators were associated with other attributes identified in the survey. We have added suggestions from respondents regarding these other attributes to those for this specific attribute in our analysis.
} 
Performance Measures for Evaluating Public Participation Activities in DOE's Office of Environmental Management

Rather than selecting one or two of the behavioral indicators suggested by the respondents (to the exclusion of other equally relevant indicators), we recommend an indicator that combines several of the behavioral indicators described above, as follows:

- The development and implementation of a decision integrating cost, schedule, environmental, safety, and health factors plus other external stakeholder concerns.

Suggestions for how to use all eight performance indicators discussed above are presented in the next chapter. 


\section{CHAPTER 5. SUMMARY AND RECOMMENDATIONS}

Chapter 5 provides a summary of key findings, our recommendations regarding how to use the recommended performance indicators in future evaluations, and a brief discussion of important factors to consider in developing, implementing, and evaluating public participation.

\section{SUMMARY OF KEY FINDINGS}

This report began with the presentation of a conceptual framework that portrayed public participation in the context of a problem-solving or decision-making system (see Fig. 1.1). That framework, and the narrative that accompanied it, indicated that regulatory authorities have traditionally had a significant role in decision-making by executive departments such as DOE. Although non-regulatory stakeholders currently enjoy a prominent role in decision-making, they have held that position of importance for a considerably shorter period of time than have regulatory agencies. Moreover, regulatory authorities' influence on executive decision-making is more powerful than that of other stakeholders given their permitting authority.

The value added by public participation to decision-making can be enhanced through better organization, improved participation strategies and mechanisms, and integration with other aspects of decision-making (including integration of stakeholders with problem definition, mission development, the identification and evaluation of decision alternatives, decision-making, and decision implementation). However, the opportunity to improve the value added by public participation is contingent on being able to demonstrate that the resources devoted to such activity is a sensible and worthwhile investment. The Office of Intergovernmental and Public Accountability in DOE's EM is committed to public participation in decision-making and is seeking mechanisms to demonstrate the worth of that investment to DOE and other decision-makers, as well as to the public.

The attributes and indicators of public participation success identified in this report are designed to document the value added by public participation and to provide a mechanism by which decision-makers and public participation specialists can identify strengths and weaknesses of their current efforts so as to do a better job. Our attributes and indicators were developed through significant interactions with stakeholders in the field - through intensive interviews and surveys with DOE project managers and public participation specialists, contractor project managers and public participation specialists, and representatives of tribal, state, and local governments, federal and state regulatory authorities, environmental interest groups, and other interested parties. As discussed in Chapter 3, our respondents individually rated attributes, and that rating process demonstrated remarkable agreement both within and across internal and external stakeholder groups (see Table 5.1). That agreement allowed us to assemble a subset of attributes focusing on the decision-making process, mutual understanding among internal and external stakeholders, trust and confidence in DOE and its local manifestations (i.e., individual DOE facilities, field offices, and activities, projects, and programs), the decisions themselves, and mission accomplishment.

The indicators for these attributes, also shown in Table 5.1, were likewise developed with the participation of the internal and external stakeholders at our study sites. Based on our request to respondents for suggested indicators of success corresponding to their "top five" attributes, we received hundreds of suggestions. Looking for commonality among the suggestions and opportunities to combine and coalesce indicators, we assembled behavioral and perceptual indicators for each of the attributes considered to be useful and important in 
Performance Measures for Evaluating Public Participation Activities in DOE's Office of Environmental Management

\begin{tabular}{|lll|}
\hline \multicolumn{3}{|c|}{ Table 5.1. Suggested attributes of success and performance } \\
indicators to use in future evaluations
\end{tabular}

future evaluations. As discussed in the next section, the use of these indicators, and particularly the use of behavioral indicators, will require some site-specific or project-specific modification.

The package of attributes and indicators we have recommended using in future evaluations should offer a means to document the value added by public participation in EM 
decision-making in the field and, when aggregated, across all EM activities in the DOE complex. The package should also be useful in identifying areas of strength and areas where improvements can be made in implementing a high-quality public participation program.

Evaluators should be cautioned, however, that the attributes and indicators are interactive, and a thorough evaluation requires the whole package. For example, the legitimacy of the decision-making process is affected by the extent to which full and active representation of stakeholders is accomplished. Similarly, a "good" decision requires consideration of all factors leading to a decision where the simultaneous accomplishment of "better-fastercheaper" can be achieved without sacrificing any of those three criteria. This caution leads to a complementary and equally important concern - any evaluation of the success of public participation should represent the varied perspectives offered by our multiple attributes and indicators. Success cannot (or should not) be ranked or aggregated to a single score because that would deny the multi-dimensionality of the concept of success. Furthermore, we acknowledge that there may be some cases that call for one or more additional attributes or indicators not recommended in this report, and there may be some cases where an evaluator wants to evaluate some attributes more frequently than others because of a perceived need to "fix" some part of a public participation activity or program.

In the following section, we suggest evaluation techniques to use when measuring the success of public participation programs in terms of the attributes and performance indicators presented above. The suggested methods are drawn from the program evaluation literature (Goldenberg and Frideres 1986; Jordan, J. M. et al. 1995; Posavac and Carey 1985; Poister 1978; and Rutman and Mowbray 1983), reports and articles on performance indicators cited in Chapter 4, the interviews with stakeholders described in Chapter 1, and the real-world experience of the authors.

\section{RECOMMENDATIONS FOR USING PERFORMANCE INDICATORS}

The appropriate use of the performance indicators in subsequent evaluations of EM public participation activities in the field and, when aggregated, across all EM activities in the DOE complex, may be subject to alternative interpretations. Some members of the public and some stakeholder groups may perceive that they may have had little or no influence on EM decision-making, while others may feel that they have had an appropriate level of influence. Some may even feel that, given how a particular EM activity or associated public participation activity was implemented, some groups had far more influence than was their due. For that reason, we strongly suggest that evaluations, whether conducted in and by the field or complex-wide by headquarters, should be conducted and reported in the open. By doing so, all stakeholders and the public will have the opportunity to review and comment on the evaluation and the validity of its conclusions. This will help assure that no viewpoints or perspectives were favored at the expense of others. ${ }^{11}$ The following discussion identifies evaluation techniques that might be used with the attributes and indicators identified in this report.

It should be noted that the following discussion of performance indicators and their use in evaluations is not focused on a particular EM activity, project, or program, and in some cases refers to all of EM or DOE. We urge the reader to identify and use the appropriate activity-, project-, or program-specific context when applying these indicators.

11 This approach does not explicitly satisfy concerns regarding whether or not all stakeholder groups and the public were advised of the opportunity to participate or, if advised, had the resources, interest, or the inclination to participate. This concern has implications for several of the performance indicators and evaluation techniques discussed below, and special efforts may need to be made to satisfy these concerns. 


\section{Performance Measures for Evaluating Public Participation Activities in DOE's Office of Environmental Management}

The Proportion of All Identifiable Stakeholder Groups That Have Taken Part in Public Participation Efforts

This performance indicator measures success according to the first attribute listed in Table 5.1 - "The decision-making process allows full and active stakeholder representation." To use this indicator, one would have to identify all stakeholder groups in the local area with an interest in the outcome of DOE's EM activities and then determine which of these stakeholders have been involved in the public participation effort(s) being evaluated. After that, it is a matter of simple mathematics to calculate what proportion of all stakeholder groups have taken part in the public participation effort(s). The meaning of the number that is produced in this fashion is not entirely clear, since there is no widely accepted grading scale to tell us what value to attach to a given score. The interested parties can probably garner some qualitative feel for how well they have done based on this single number, but the usefulness of the measure increases substantially when it is used to compare a particular public participation effort with some other effort (either on-site or at another facility) or to examine the same project at two or more points in time. We assume that public participation efforts that involve a greater proportion of all relevant stakeholder groups are better than those that are less inclusive, although the interested parties would do well to examine the specific groups that are involved and consider how well they represent the breadth and depth of important community interests. ${ }^{12}$ Perhaps the most valuable result of using this performance indicator is that it requires the agency performing the evaluation (presumably DOE) to identify all stakeholder groups and see how many of them have been involved with local public participation efforts. The simple act of doing this allows the interested parties to see which stakeholders have been absent and should possibly be recruited for future public involvement efforts.

\section{The Mechanisms Used to Attract, Engage, and Maintain the Interest of Stakeholders Throughout the Public Participation Effort}

Like the preceding performance indicator, this one also is associated with the first attribute of success listed in Table 5.1, but it lacks the quantitative nature of the first measure. Instead, it is a listing of all mechanisms used to alert and recruit stakeholders and keep them involved with the public participation efforts in question. We recommend that this list be compared with a listing of the key public participation devices in use at other sites around the country (Appendix D). Once again, the act of self-examination allows and encourages the interested parties to take stock of how they are conducting their public participation efforts. And the subsequent comparison of one's own techniques for attracting, engaging, and maintaining the interest of stakeholders with a broad list of approaches used at other sites can provide evaluators and public participation specialists with new ideas and stimulate them to consider whether any of the devices not in use at their site would be appropriate to adopt. We recommend going through each public participation technique that they use and ask themselves why they being used and then go through each of the approaches listed in Appendix $\mathrm{D}$ and, for those that are not in use, consider why they are not being utilized and whether they could be beneficial.

\footnotetext{
12 The relative importance of different stakeholder groups to making and implementing a durable as well as an efficient and effective decision could also be considered. In other words, although it would be highly desirable to develop a decision characterized by unanimous consent among all stakeholders, some stakeholders (e.g., those who have some constitutional or statutory authority over the decision, such as regulatory agencies) may be more important than others.
} 


\section{Performance Measures for Evaluating Public Participation Activities in DOE's Office of Environmental Management}

Participants' Evaluation of the Legitimacy of Decision-Making Processes at Various Stages in the Decisions Cycle for the EM Activity in Question

This performance indicator measures success according to the second attribute listed in Table 5.1 - "The decision-making process is accepted as legitimate by stakeholders." We suggest that all individuals involved in the public participation process be surveyed regarding their perception of the legitimacy of the decision-making process. To avoid confusion over the meaning of the term "legitimacy," we suggest that it be clearly defined in the question, perhaps as follows:

Using the following five-point scale, please indicate the extent to which the decisionmaking process was conducted fairly and served the broad public interest. [1=Not at all; $2=$ Slightly; $3=$ Moderately; $4=$ Substantially; 5=Completely]

We acknowledge that there are other ways in which this question could be worded and other descriptors that could be attached to each possible answer. Also, some evaluators might prefer a seven or nine point scale because of the finer gradations that such scales provide.

It does not make sense to address the above question to non-participants, because they presumably would not know enough about the decision-making process (and its complexity for many EM activities) to allow them to give a meaningful answer. However, each participant should be asked to answer this question at a number of different points in the public participation process, thereby allowing the evaluating agency to see how the perceived legitimacy of the process changes with the passage of time, with changes in the key issues under consideration, and (if applicable) with modifications in the public participation approach used. By employing a five-point (or seven-point or nine-point) scale with explicit meanings accompanying each numeric value, we make it fairly easy to interpret the meaning of the respondents' answers. At any given time, answers can be examined for key individuals, for respondents affiliated with a specific type of organization (e.g., environmental/health groups), and for all participants as a whole. It might also be helpful to examine changes over time for key individuals and specific types of participating organizations, as well as for the entire group.

We suggest that the question described above be part of a broader survey instrument containing all those questions needed to evaluate success according to the entire set of recommended performance indicators. While it would be possible to ask these questions in person or over the telephone, we recommend that a written survey be used so that respondents have as much time as necessary to consider the questions and become familiar with the numeric scale in which they will express their answers.

\section{Internal and External Stakeholders' Ability to Identify Each Others' Concerns and Understand the Bases of Those Concerns}

The third attribute shown in Table 5.1- "DOE and other stakeholders understand each others' concerns"-is addressed by this performance indicator. We suggest that each person involved in the public participation effort be asked to list the major concerns of and constraints on every other stakeholder group participating in the process. Each participant should further be asked to explain the bases of those concerns (i.e, the chief objectives and motivations of their counterparts from other organizations and, in the case of DOE and its contractors, from other departments within their own organization). ${ }^{13}$ By examining the

13 This approach may need to be modified if the number of active stakeholder groups is large (e.g., greater than 10). The intent of the indicator is to examine the extent to which internal and external stakeholders understand and are sensitive to alternative perspectives. 


\section{Performance Measures for Evaluating Public Participation Activities in DOE's Office of Environmental Management}

answers from all respondents, the evaluators can see how well-informed the various participating parties are and can choose to disseminate additional information, as needed, to address any deficiencies in understanding. Of course, in order to identify where such deficiencies exist, the evaluating agency itself would have to know the chief concerns and their bases for each participating group, and this would probably necessitate interviews with all stakeholders to elicit this information. The very act of gathering these data would have the positive effect of informing the evaluating agency about the concerns and motivations of all other stakeholder groups. By repeating the evaluation over time, DOE can see how mutual understanding changes over the life of the public participation effort and also can keep informed as to what concerns are most vital to other participants.

\section{The Public's Self-reported Levels of Trust and Confidence in DOE and its Contractors}

This performance indicator measures success according to the fourth attribute in Table 5.1 - "The public has trust and confidence in DOE and the DOE facility." In contrast to the first subjective indicator that we discussed, we suggest that-in addition to those individuals involved in the public participation process-representatives of the public at large be surveyed on this item. To elicit the desired information, the question could be worded in this way:

Using the following five-point scale, please indicate the extent to which you have trust and confidence in the ability and intent of DOE officials and associated contractors to perform their duties in a way that serves the broad public interest.

[1=Not at all; 2=Slightly; 3=Moderately; 4=Substantially; 5=Completely]

This query could be expanded into two separate questions, one asking about DOE officials serving the facility under study and the other about officials at DOE headquarters, if such a distinction is important to those conducting the evaluation. We know that there are other ways in which this question could be worded and other scales that could be used. In particular, evaluators might want to define trust and confidence in a way that is especially relevant to their specific site or project.

For this indicator, it makes sense to query both participants and non-participants, because both are likely to have attitudes and opinions concerning DOE. Also, by surveying the population at large, we are able to compare the answers of participants and non-participants (i.e., to use non- participants as a control group) and see how involvement in public participation efforts affects people's trust and confidence in DOE. This question should be asked as early as possible-preferably before the initiation of public participation efforts-in order to provide a baseline level of public trust and confidence. Then, the same question should be asked periodically to document how the answers of participants and nonparticipants change over time. The use of a control group and the collection of time-series data both make it possible to identify how the public participation efforts under study affect trust and confidence and to attribute this causality with more certainty than would be the case in the absence of these devices. And, as with other survey questions, the data can be searched for differences among respondents based on their primary organizational affiliation.

\section{Judgments by Internal and External Stakeholders That Public Participation Has Led to Better Decisions}

The fifth attribute from Table 5.1_-"Key decisions are improved by public participation"-is addressed by this performance indicator. We suggest that only those individuals involved in the public participation process be surveyed regarding their perception of the extent to which decisions have been affected by public participation; nonparticipants are excluded because they are not likely to have enough information to 
meaningfully answer a question on this subject. We suggest the following wording for this question:

Using the following five-point scale, please indicate the way in which important decisions have been affected by the public participation effort[s] in question. [ $1=$ Very negatively; $2=$ Somewhat negatively; $3=$ Neither positively nor negatively; $4=$ Somewhat positively; $5=$ Very positively]

It would be possible to ask this question in terms of improvements only (ranging from none to substantial), but we believe that the wording suggested above is appropriate because it acknowledges that some respondents could believe that public participation has degraded the quality of decisions. A seven or nine point scale could be useful for this question because of the broad range of possible responses contained between the two poles.

As with previous questions, this question could be asked at different points in time; as noted in Chapter 4 , we believe that the periodic posing of this question can produce feedback that would improve the decisions that are made. However, this question cannot be posed initially until the public participation process has been in existence long enough to result in important decisions. Subsequent administrations of this question could document how attitudes change as additional decisions are made. The explicit definitions attached to each of our possible numeric answers makes it fairly easy to interpret the answers and, as with previous questions, comparison of responses among groups could be enlightening.

\section{Participants' Evaluation of the Legitimacy of Decisions for a Given EM Activity}

This performance indicator measures success according to the sixth attribute listed in Table 5.1 - "Key decisions are accepted as legitimate by stakeholders." We suggest that all individuals involved in the public participation process be surveyed regarding their perception of the legitimacy of the important decisions that have been made. Nonparticipants should not be queried, for reasons explained previously. We suggest that the question associated with this indicator be worded as follows:

Using the following five-point scale, please indicate the extent to which important decisions are fair and serve the broad public interest.

[1=Not at all; 2=Slightly; 3=Moderately; 4=Substantially; 5=Completely]

Once again, we acknowledge that there are other ways in which this question could be worded and other numeric scales and descriptors that could be used. Also, evaluators can modify the question to focus on specific decisions that are of special import to the public participation efforts under study.

The survey containing the above question should be administered to all participants at a number of different points in the public participation process, so that the evaluator can track how the perceived legitimacy of key decisions varies with the passage of time and with the nature of the decisions that are made. Because the suggested five-point scale has explicit descriptors accompanying each numeric value, interpreting the meaning of the respondents' answers is fairly straight-forward. And, as with other questions, evaluators can examine the answers and how they change over time for key individuals and different organizational types. 


\section{Performance Measures for Evaluating Public Participation Activities in DOE's Office of Environmental Management}

The Development and Implementation of a Decision Integrating Cost, Schedule, Environmental, Safety, and Health Factors Plus Other External Stakeholder Concerns

This performance indicator is associated with the final attribute of success shown in Table 5.1 - "DOE's site-specific mission is accomplished." To measure success according to this indicator, the evaluating agency must inspect the decision ${ }^{14}$ that is reached and examine the associated costs, schedule, environmental impacts, health and safety implications, and the effects in any other areas (e.g., community well-being and local employment) that are important to external stakeholder groups. Program evaluators must become familiar with DOE's site-specific mission and stakeholders' concerns (if they are not already) by interviewing key personnel and reviewing relevant reports, planning documents, and mission statements. They can then deal with the question (sometimes quantitatively and other times qualitatively) of how well the actions described in the decision fulfill that mission and address those concerns. This evaluation will require a substantial amount of site-specific investigation and can only be fully undertaken following the completion of EM activities leading up to the decision at the site in question. However, once completed, this investigation should yield a wealth of valuable information concerning how well DOE's site-specific mission has been accomplished.

\section{CONCLUSIONS}

Public participation in EM activities throughout the DOE complex is a critical component of the overall success of remediation and waste management efforts. The challenges facing EM and its stakeholders over the next decade or more are daunting (Nuclear Waste News 1996). Achieving a mission composed of such challenges will require innovation, dedication, and a significant degree of good will among all stakeholders.

EM's efforts to date, including obtaining and using inputs offered by EM stakeholders, have been notable. Public participation specialists have accepted and met challenges and have consistently tried to improve their performance. They have reported their experiences both formally and informally (e.g., at professional conferences and EM Public Participation Network Workshops, other internal meetings of DOE and contractor public participation specialists, and one-on-one consultations) in order to advance the state of their practice.

Our research, and our field research in particular (including our interactions with many representatives of numerous stakeholder groups at nine DOE sites with diverse EM problems), have shown that it is possible to develop coherent results even in a problem domain as complex as that of EM. We conclude that performance-based evaluations of public participation appear possible, and we have recommended an approach, based on combined and integrated multi-stakeholder views on the attributes of successful public participation and associated performance indicators, that seems workable and should be acceptable to diverse stakeholders. Of course, as an untested recommendation, our approach needs the validation that can only be achieved by application (perhaps at a few DOE sites with ongoing EM activities). Such an application would serve to refine the proposed approach in terms of its clarity, its workability, and its potential for full-scale use by EM and, potentially, other government agencies and private sector concerns.

Periodic evaluations of public participation activities, whether performed locally in an ad hoc manner, as systematic site-specific or project-specific self-assessments, or nationally, should result in improved understanding and performance. These studies should enhance the

\footnotetext{
14 Public participation is important in making and implementing many kinds of decisions, including but not limited to technology choice, site selection, permitting decisions, interim decisions, and RODs. "Decision" is used here more loosely to maintain the flexibility needed to accommodate diverse applications.
} 
ability of all stakeholders, internal and external, to meet the challenges facing EM. It is our hope that the information and recommendations contained in this report will assist DOE and its contractors as well as external stakeholders in accurately measuring the effects of public participation efforts and identifying ways in which the value they add to EM activities can be increased. 


\section{REFERENCES}

Alinsky, S.D., 1946. Reveille for Radicals. Chicago: University of Chicago Press.

Arnstein, S.R., 1969. "A Ladder of Citizen Participation," Journal of the American Institute of Planners," 29:4 (July 1969):216-24.

Bardach, E., 1977. The Implementation Game. Cambridge, MA: MIT Press).

Baumgartner, F.R., and B.D. Jones, 1993. Agendas and Instability in American Politics. Chicago: University of Chicago Press.

Beck, D.M., C.C. Kelly, and E. Forbes 1995, "Success Stories? An Analysis of Stakeholder Involvement in the Department of Energy's Office of Environmental Management," Environmental Challenges: The Next 20 Years. NAEP 20th Annual Conference Proceedings, National Association of Environmental Professionals, June.

Bosso, C.J., 1994. "The Contextual Bases of Problem Definition," 182-203, in Rochefort, David A. and Roger W. Cobb, eds. 1994. The Politics of Problem Definition. Lawrence, KA: University of Kansas Press.

Fisher, R., and W. Ury, 1983. Getting to Yes. New York: Penguin Books.

Goldenberg, S. and J. S. Frideres 1986. "Measuring the Effects of Public Participation Programs," Environmental Impact Assessment Review, 6 (3): 273-81.

Hilgartner, S. and C.L. Bosk, 1988. "The Rise and Fall of Social Problems: A Public Arenas Model," American Journal of Sociology 94: 53-78.

Hutcheson, Jr., J.D. and J. Shevin, 1976. Citizen Groups in Local Politics. Santa Barbara, CA: Clio Books.

Jordan, J. M., et. al. 1995. Fernald Envoy Assessment, Center for Environmental Communication Studies, University of Cincinnati, Cincinnati, Ohio.

Kraft, M. E., 1988. "Evaluating Technology Through Public Participation: The Nuclear Waste Disposal Controversy," pp. 253-77, in Kraft, M. E. and N. J. Vig, eds., 1988. Technology and Politics. Durham, NC: Duke University Press.

Lach, D., P. Hixson, and L. Ramonas 1995, "Prototype Indicators of Value Added through Public Involvement," Environmental Challenges: The Next 20 Years. NAEP 20th Annual Conference Proceedings, 264-75, National Association of Environmental Professionals, June.

Lindblom, C.E., 1990. Inquiry and Change. New Haven: Yale University Press.

Lowi, T. J., B. Ginsberg, E. J. Feldman, G. J. Nigosian, J. Pool, A. Rosenbaum, C. Rottsolk, M. Stapleton, J. Van Herik, J. Vitullo-Martin, and T. Vitullo-Martin, 1976. Poliscide. New York: Macmillan Publishing Co., Inc.

Maguire, L.A., 1995, Desired Future Conditions for the Chattooga Watershed: A Qualitative Analysis of Diverse Public Opinions, Report to the Southeastern Forest Experiment Station, USDA Forest Service, October.

Mansbridge, J.J., ed., 1990. Beyond Self-Interest. Chicago: University of Chicago Press. 
Milbrath, L. W., 1981. "Incorporating the Views of the Uninterested but Impacted Public in Environmental Planning," pp. 101-112, in J. G. Grumm and S. L. Wasby, eds., The Analysis of Policy Impact. Lexington, MA: Lexington Books.

Nuclear Waste News, 1996, 16 (26): 253-254 (June 27, 1996).

Phibbs, P., 1996. "National Research Council Panel Outlines New Approach to Risk," Nuclear Waste News 16 (24):235-236 (June 13, 1996) and "Commission Recommends Systematic Approach to Assess, Manage Risks," Nuclear Waste News 16 (25) 247-248 (June 20, 1996).

Poister, T. H. 1978. Public Program Analysis: Applied Research Methods, University Park Press, Baltimore, Maryland.

Posavac, E. J. and R. G. Carey, 1985. Program Evaluation: Methods and Case Studies, Prentice-Hall, Inc., Englewood Cliffs, New Jersey.

Pressman, J. L., and A. B. Wildavsky, 1973. Implementation. Berkeley: University of California Press.

Rochefort, David A. and Roger W. Cobb, eds. 1994. The Politics of Problem Definition. Lawrence, KA: University of Kansas Press.

Rosener, J.B., 1978, "Citizen Participation: Can We Measure its Effectiveness?" Public Administration Review, No. 5, September/October.

Rutman, L. and G. Mowbray 1983. Understanding Program Evaluation, Sage Human Services Guides, Volume 31, Sage Publications, Newbury Park, California.

Schattschneider, E. E., 1960. The Semi-Sovereign People. New York: Holt, Rinehart and Winston.

Shklar, J.N., 1990. The Faces of Injustice. New Haven: Yale University Press.

Syme, G.J., and B.S. Sadler 1994, "Evaluation of Public Involvement in Water Resources Planning, A Researcher-Practitioner Dialogue," Evaluation Review, Vol. 18, No. 5, October.

Tyler, T.R., 1990. "Justice, Self-Interest, and the Legitimacy of Legal and Political Authority," pp. 171-179, in Mansbridge, J.J., ed., 1990. Beyond Self-Interest. Chicago: University of Chicago Press.

U.S. Department of Energy, 1994a, FY 1995 Performance Plan, Office of Environmental Management, Washington, D.C.

U.S. Department of Energy 1994b, Office of Public Accountability EM-5, Program Plan, Office of Environmental Management, Washington, D.C.

U.S. Department of Energy 1994c, Public Participation Desk Reference, Office of Environmental Management, Washington, D.C., November.

U.S. Department of Energy 1995a, Environmental Management 1995, Progress and Plans of the Environmental Management Program, DOE/EM-0228, Washington, D.C., February. 
Performance Measures for Evaluating Public Participation Activities in DOE's Office of Environmental Management

U.S. Department of Energy 1995b, Estimating the Cold War Mortgage, The 1995 Baseline Environmental Management Report, Volumes 1 and 2, DOE/EM-0232, Washington, D.C., March.

Young, C., G. Williams, and M. Goldberg 1993, Evaluating the Effectiveness of Public Meetings and Workshops: A New Approach for Improving DOE Public Involvement, ANL/EAIS/TM-100, Argonne National Laboratory, Argonne, Illinois, July. 


\section{APPENDIX A. ORAL DATA COLLECTION PROTOCOL}




\section{FINAL DATA COLLECTION PROTOCOL (January 1996)}

\section{Introduction}

Hello. We are Oak Ridge National Laboratory staff working for DOE to help identify performance indicators to use in evaluating DOE's public participation efforts. We are interviewing people like yourself who have experience with public participation. We are not performing an evaluation at this time, but are only gathering information on how to appropriately evaluate public participation efforts in the future. Your participation in this study is voluntary. We will not identify you as the source of the specific answers that you provide (although we will list you in our report as a respondent). As we told you when we set up this interview, we are interested in your experiences with public participation related to <specific program or activity>. We are also interviewing a number of other people involved with the same program [or activity] as well as people in a number of other areas who are involved with a variety of other public participation efforts. This interview will take approximately $<30$ minutes to two hours $>$. We will begin with some background questions regarding your job and your public participation experience.

\section{Personal Information about Respondent}

1. What is your current title and position?

2. How many years have you held the above-mentioned position?

3. Do you currently have a role related to public participation? If so, what is it?

4. How many years have you been involved in public participation work (including the above-mentioned effort)? As for number of years only; do NOT ask for listing of positions or description of experiences.

5. What is your disciplinary training (degrees, etc.)?

\section{Types of DOE Public Participation Efforts Undertaken to Date}

Note: We will focus on a specific environmental management activity or program and then explore ALL the public participation mechanisms used to get input related to that project.

1. Describe the public participation effort(s) taken in relation to the EM program/activity in which we are interested. Only ask directly for information on EM program/activity if we need it to supplement published descriptions. Start by asking EM project manager. We need about one page worth of accurate descriptive information.

2. Is/was the public participation effort important? If so, why?

3. How long has the above-mentioned public participation effort lasted?

4. How much time and money have you and your organization committed to the public participation effort?

5. What were the underlying objectives of the above-mentioned environmental management program or activity?

6. What were the underlying objectives of the public participation effort(s)? 


\section{Performance Measures for Evaluating Public Participation Activities in DOE's Office of Environmental Management}

7. List the key stakeholder groups - internal and external - involved in the abovementioned public participation effort(s)?

8. What are your group's principal goals and objectives? Do NOT ask this for groups with broad, multi-purpose objectives (e.g., DOE, state EPA).

9. What does your group want to accomplish through its involvement with the abovementioned public participation efforts?

10. What connections, if any, do you think there are between public participation efforts and the decision-making process? [To get at "critical assumptions" and "conceptual framework:]

\section{Additional Information about Organization and Implementation of Public Participation Efforts}

Note: Ask these questions only of the DOE and M\&O contractor program manager and public participation specialist.

4. ' Does DOE project management take "ownership" of the public participation effort or is public participation primarily the domain of PP specialists?

\section{Criteria for Evaluating DOE's Public Participation Efforts}

Note: Administer attatched survey or leave with interviewee to return to ORNL after completing it.

\section{Research Methods for Evaluating DOE's Public Participation Efforts}

1. Have you ever formally evaluated or tried to evaluate your public participation efforts? [If not, skip to Section VI.] Note: This question refers only to formal evaluations and NOT to more intuitive "lessons learned."

2. In your own evaluations of public participation efforts, what methods have you used to collect, analyze, and interpret data?

3. What are the advantages and disadvantages of the approach(es) to evaluating public participation efforts that you have employed?

\section{Major Factors Explaining Success of DOE's Public Participation Efforts}

1. On a five-point scale (with one being lowest and five being highest), rate the success of the public participation effort(s) that we have been discussing.

2. What major factors led to the level of success you described above?

3. What actions could have improved the success of these public participation efforts?

\footnotetext{
${ }^{a}$ We have retained the numbering used in previous protocols to allow easy comparison across sites of answers to this question.
} 


\section{Performance Measures for Evaluating Public Participation Activities in $D O E$ 's Office of Environmental Management}

4. If you had a magic wand, what one or two changes or "fixes" in public participation programs would you make?

\section{Closing}

Thank you very much for your cooperation. Is there anything else you'd like to say about any of the issues that we've raised in this interview? 
Performance Measures for Evaluating Public Participation Activities in DOE's Office of Environmental Management

\section{APPENDIX B. WRITTEN SURVEY}




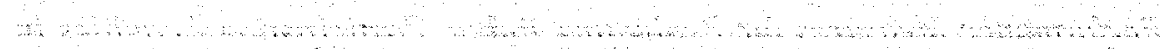

$\because$ 


\section{Criteria for Evaluating DOE's Public Participation Efforts}

1. Listed below are a number of possible ways to define success for public participation programs. Using the five-point scale presented here, please indicate how important you believe each item is for evaluating the success of the DOE public participation efforts with which you have been involved.

\section{$1=$ Not Important 3= Moderately Important 5=Essential}

\section{2= Slightly Important \\ $4=$ Very Important}

(a) The extent to which the decision-making process allows full and active stakeholder representation.

Circle

$\underline{\text { One }}$

(b) The extent to which the decision-making process is accepted as legitimate by stakeholders.

(c) The extent to which the public understands DOE's environmental management problems and associated actions.

(d) The extent to which DOE is presented with comprehensive and thoughtful input by the public.

(e) The extent to which DOE understands public concerns.

(f) The extent to which key decisions are influenced by the public.

(g) The extent to which key decisions are improved by public participation. 12345

(h) The extent to which key decisions are accepted as legitimate by stakeholders.

(i) The extent to which the public has trust and confidence in DOE and the DOE facility in general.

(j) The extent to which environmental management costs are minimized. $\quad 12345$

(k) The extent to which adverse environmental impacts are minimized.

(l) The extent to which the public understands the connection between clean-up costs and environmental benefits.

(m) The extent to which any adverse impacts are distributed equitably among the public.

(n) The extent to which stakeholder (DOE and non-DOE) objectives for a particular public participation effort are met.

(o) The extent to which DOE's site-specific mission is accomplished.

(p) The extent to which the overall objectives of non-DOE stakeholders

(q) Other (Please define) 
2. Of all the definitions of success listed on the previous page, which five do you consider most important for evaluating DOE's public participation efforts? Identify each definition by its letter.

3. "Performance Indicators" are measurable factors that can be used to gauge how well a public participation program does according to a particular definition of success.

For example, performance indicators for definition (o) - the extent to which DOE's site- specific mission is accomplished-could include the number of acres remediated and the speed at which clean-up efforts are completed. Performance indicators for definition $(p)$ - the extent to which the overall objectives of non-DOE stakeholders are met - could include changes in local property values and improvements in groundwater quality.

\section{Please suggest performance indicators for the following definitions of success:}

(n) The extent to which your objectives for this public participation effort are met.

(o) The extent to which DOE's site-specific mission is accomplished.

(p) The extent to which the overall objectives of non-DOE stakeholders are met. 
4. If you can think of appropriate performance indicators for any of the five definitions of success that you listed on the previous page as being most important for evaluating DOE's public participation efforts, please give the definition's letter and your suggested performance indicator(s):

Letter

Suggested performance indicators

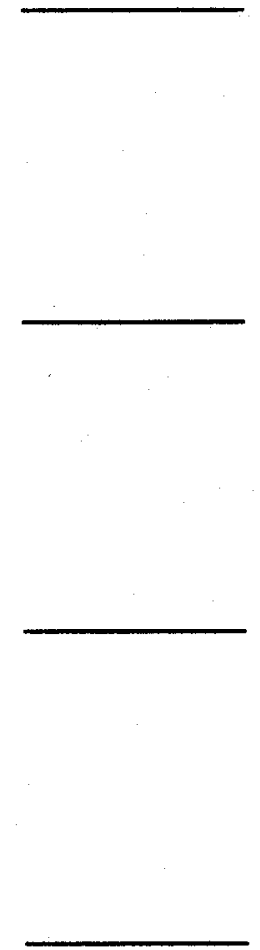


Performance Measures for Evaluating Public Participation Activities in DOE's Office of Environmental Management

\section{APPENDIX C. LIST OF INTERVIEWEES, BY SITE}




\section{APPENDIX C. LIST OF INTERVIEWEES, BY SITE}

\section{Ambrosia Lake, NM (UMTRA)}

Michael Abrams, Site Manager, Uranium Mill Tailing Remedial Action Project, DOE

Albuquerque Operations Office

Larry Carver, President, Carver Oil Company, Milan, NM

Fred Craft, Manager, Homestake Mining Company

Bill Dawson, County Commissioner, District 4, Cibola County

Terry Fletcher, General Manager, Quivera Mining Company

Jonnie Head, Jonnie Head Real Estate, Grants

Melvin Head, former uranium miner and superintendent

Chuck Hundertmark, Public Affairs specialist, Jacobs Engineering Group, Inc.

Tom Jackson, Superintendent, Grants/Cibola County Schools

Juan Juanico, First Lieutenant Governor, Pueblo of Acoma

Mary Beth Leaf, Site Manager, Jacobs Engineering Group, Inc.

Melanie Majors, Public Affairs Specialist, Jacobs Engineering Group, Inc.

Roberta Marquez, Office Manager, Cibola County, and landowner at site

Warren Mathers, Mayor, City of Milan, NM

Fred Morgan, Manager, Public Affairs, Jacobs Engineering Group, Inc.

Joseph Murrietta, County Manager, Cibola County

Stanley Paytiamo, Environmental Protection Specialist, Environmental Protection Agency, Pueblo of Acoma

Bill Snodgrass, Mayor, City of Grants

\section{Fernald Environmental Management Project (FEMP), OH}

Randy Allen, Project Manager, DOE, Operable Unit 4

Dennis Carr. Project Manager, FERMCO

Peggy Collins, Co-President, Hamilton-Fairfield Area League of Women Voters

Jack Craig, Director, DOE Fernald Area Office

Lisa Crawford, President, Fernald Residents for Environment, Safety, and Health (FRESH)

Pam Dunn, Fernald Residents for Environment, Safety, and Health (FRESH)

Laura Hafer, Fernald Public Outreach Coordinator, Ohio Environmental Protection Agency

Jane Harper, Trustee, Crosby Township

Jack Hoopes, Director of Public Affairs, Fernald Environmental Restoration Management

Corp. (FERMCO)

Chuck Hundertmark, Senior Public Information Specialist, Jacobs Engineering Group, Inc.

Gene Jablonowsky, Region V, U.S. Environmental Protection Agency

Rob Janke, Operable Unit 5 Team Leader, DOE Fernald Area Office

Graham Mitchell, Chief, Office of Federal Facilities Oversight, Ohio Environmental Protection Agency

Ken Morgan, Director of Public Affairs, DOE Ohio Operations Office

Doug Sarno, consultant to Citizen Action Group

Tom Schneider, Fernald Project Manager, Ohio Environmental Protection Agency

Gary Stegner, Public Affairs Officer, DOE Fernald Area Office

Bob Tabor, CAB member, Fernald Atomic Trades and Labor Council

Dave Young, Trustee, Ross Township 


\section{Oak Ridge Reservation (ORR), TN}

Tony Able, Region IV, U.S. Environmental Protection Agency

Karen Bowdle, Community Relations Program, Lockheed Martin Energy Systems, Inc.

Al Brooks, property owner

Walter Brown, Member, Oak Ridge City Council

Wayne Clark, property owner

Amy Fitzgerald, Executive Director, Oak Ridge Local Oversight Committee

Susan Gawarecki, League of Women Voters

Jack Hanley, Agency for Toxic Substances and Disease Registry

Fred Hannon, property owner

Bill Issel, Manager, Community Development, City of Oak Ridge

Fred Maienschein, concerned citizen

Doug McCoy, DOE Oversight Division, Tennessee Department of Environment and Conservation

David Page, Program Manager for East Fork Poplar Creek, DOE Oak Ridge Operations

Diantha Paré, President, League of Women Voters

Bob Peelle, former Commissioner, Roane County

Sandy Perkins, Public Participation Specialist for East Fork Poplar Creek, DOE Oak Ridge Operations

Sandra Reid, RN, Founder, Oak Ridge Health Liaison

Ellen Smith, Chair, Environmental Quality Advisory Board, City of Oak Ridge

Claudia Souleyrette, Citizens for Better Health

Wayne Tolbert, Science Applications International Corporation

\section{Sandia National Laboratories (SNL), NM}

Lloyd Aker, Site Manager, DOE Oversight Bureau, New Mexico Environment Department

Richard Brusuelas, Director, Environmental Health Department, Bernalillo County

Lois Chemistruck, Member, CAMU Working Group

Rarilee Conway, Task Leader - Technical Area II, Environmental Restoration Project, Sandia National Laboratories

Wendy Davis, Member, CAMU Working Group

Jim Fish, Technical Staff, Technical Area II, Environmental Restoration Project, Sandia National Laboratories

Mario Guggino, Member, Citizen Advisory Board

Will Keener, Public Participation Task Leader, Sandia National Laboratories

Stephanie Kruse, RCRA Permitting Program, Hazardous and Radioactive Materials Bureau, New Mexico Environment Department

Curt Montman, Manager, Environmental Services Division, City of Albuquerque

Fran Nimick, Manager, Environmental Restoration Department, Sandia National Laboratories

Beth Oms, CAMU Project Manager, DOE Albuquerque Operations Office/Kirtland Area Office

W. Paul Robinson, Executive Director, Southwest Research and Information Center

Chris Shuey, Senior Project Staff, Southwest Research and Information Center

Jay Sorensen, Member, Citizen Advisory Board

Bob Sweeney, Technical Compliance Division, Hazardous and Radioactive Materials Bureau, New Mexico Environment Department

Dianne Terry, Member, Citizen Advisory Board 


\section{Savannah River Site (SRS), SC}

Joan Baum, DOE Savannah River Office, Waste Area Group Manager for F and H Groundwater

Susan Bloomfield, Nuclear Waste and Natural Resources Chairs, Sierra Club and League of Women Voters, Augusta, GA

Fred Cavanaugh, Jr., Mayor of Aiken, South Carolina

Keith Collingsworth, Federal Facilities Agreement Coordinator, South Carolina Department of Health and Environmental Control

Brian Costner, Director, Energy Research Foundation, Columbia, SC

Virginia Gardner, Public Accountability Program, DOE Savannah River Office

Dawn Haygood, Public Involvement specialist, Westinghouse

Al Hodge, President, Metropolitan Augusta Chamber of Commerce

Bill Lawless, Professor, Paine College

Anne Loadholt, Citizens' Advisory Board and Barnwell County Council

Dean Moss, Manager, Beaufort-Jasper Water Utility

Lee Poe, Concerned Citizen and Consultant to Citizens' Advisory Board

Bill Shepard, Administrator, Aiken County

P. K. Smith, Senior Engineer for Excess Facilities Spent Fuel Storage Program, DOE Savanna River Office

Tom Temples, Geotechnical Support Manager, DOE Savannah River Office

Eric Thompson, Executive Director, Lower Savannah Council of Governments

Camilla Warren, Region IV, U.S. Environmental Protection Agency

\section{Stanford Linear Accelerator Center (SLAC), CA}

Leonie Batkon, Manager of Lands Management, Stanford University

Karen Cotter, Program Coordinator of Streamkeeper Program, Coyote Creek Riparian Station Peter Drekmier, Director, Bay Area Action

Kim Efishoff, Program Manager for SLAC Restoration Activities, DOE Oakland Operations Office

Ron Gervason, Senior Engineering Geologist, San Francisco Bay Area Regional Water Quality Control Board

Sam Herzberg, Planning and Building Division, Environmental Resources Administration of San Mateo County

Jim Johnson, Friends of San Francisquito Creek

Rick Miller, Hazardous Materials Inspector, Environmental Health Services, San Mateo County

Trish Mulvey, Co-Founder, Clean South Bay

Debbie Mytels, Project Coordinator, San Francisquito Creek Coordinated Resource Management and Planning Process

Marilyn Walter, Conservation Committee, Portola Valley, California 


\section{Wayne (FUSRAP), NJ}

Angela Carpenter, Remediation Project Manager, Region II, U.S. Environmental Protection Agency

Andrew Drol, Concerned Citizen, member, Wayne Thorium Committee

John Michael Japp, Site Manager, Wayne Site, DOE Oak Ridge Operations

Mary Ann Orapello, Director, Health and Welfare, Wayne Township

Sandra Plant, Manager, Community Relations for Formerly Utilized Sites Remedial Action Program (FUSRAP), Bechtel International

Stuart Price, Information Coordinator, Bechtel International

Michael Redmon, Project Manager for New Jersey and Opportunity Sites, Formerly Utilized Sites Remedial Action Program (FUSRAP), Bechtel International

Wayne Scarborough, Community Affairs Supervisor for New Jersey and Opportunity Sites, Formerly Utilized Sites Remedial Action Program (FUSRAP), Bechtel International

\section{Weldon Spring Site Remedial Action Project (WSSRAP), MO}

Daryl Anderson, Weldon Spring Citizens Commission

Elaine Blodgett, Vice Chair, Saint Charles County Citizens Commission

Dan Brown, Assistant Superintendent, Francis Howell School District

Margaret Culver, Board of Aldermen, Weldon Spring

Jim Garr, Wildlife Management Biologist/Public Use Specialist, Missouri Department of Conservation

Robert Geller, Chief of Federal Facilities Section, Hazardous Waste Program, Missouri

Department of Natural Resources

Glen Hachey, Chair, Saint Charles County Citizens Commission

Mary Halliday, former Vice President, Saint Charles Countians Against Hazardous Waste

Steve McCracken, Project Manager, DOE Weldon Spring Site

Linda Meyer, Manager of Community Relations for WSSRAP, Jacobs Engineering

Ken Meyer, Project Manager, Jacobs Engineering

Paul Mydler, Weldon Spring Citizens Commission

Roger Pryor, Executive Director, Missouri Coalition for the Environment

Jerry Van Fossen, Deputy Project Manager, DOE Weldon Spring Site

Daniel Wall, Remedial Project Manager, U.S. Environmental Protection Agency Region VII

\section{West Valley Demonstration Project, NY}

Tom Attridge, Community Relations Manager, New York State Energy Research and

Development Agency

John Chamberlain, Community Relations Manager, Westinghouse

Chuck Couture, President, West Valley Chamber of Commerce

Bill King, Supervisor, Town of Ashford, NY

Jack Krajewski, On-site monitor for RCRA program, New York State Energy Research and Development Agency

Wayne McNeil, Vice President, Gerwitz and McNeil Electric Company, West Valley, NY

Carol Mongerson, Founder, Coalition on West Valley Nuclear Wastes,

Joe Patti, Owner, West Valley Hardware and Supply and Hachias Home Service

Paul Piciulo, Director, West Valley Site Management Project, New York State Energy Research and Development Agency

Tom Rowland, Project Director, DOE West Valley Area Office

Dan Sullivan, Environmental Impact Statement Project Manager, DOE

John Thompson, Superintendent, West Valley Central School

Ray Vaughn, Founder, West Valley Coalition on Nuclear Wastes 


\section{APPENDIX D. KEY PUBLIC PARTICIPATION DEVICES USED AT DOE SITES}

This Appendix presents a selected list of methods used at our case study sites to attract, engage, and maintain the interest of stakeholders. The various approaches discussed here are groups into three important categories: (1) methods used to advertise public participation activities; (2) timing and location of public participation activities; and (3) types of public participation activities utilized. While our list is not exhaustive, it does contain many of the public participation devices that have been used for EM activities at DOE sites around the country and that influence the extent to which full and active stakeholder representation is achieved.

\section{METHODS USED TO ADVERTISE PUBLIC PARTICIPATION ACTIVITIES}

The following mechanisms are available to alert the public concerning planned public participation activities:

- Mailings about specific events, directed either at a mass audience or targeted to key individuals or groups

- Telephone invitations issued to key individuals or organizations

- Announcements and circulars distributed at public meetings

- Posters and notices displayed in public areas

- Newspaper and radio announcements

- Recordings on an " 800 " number for information on line

- Notices in the EM site's newsletter and progress reports

- Inclusion in the EM site's official calendar

\section{TIMING AND LOCATION OF PUBLIC PARTICIPATION ACTIVITIES}

Three key factors - day and time, frequency, and location - determine how easily accessible public participation activities will be to interested individuals and groups. The available options associated with each of these factors is identified separately, below.

\section{Day and time}

- Organizers can choose between weekday and weekend sessions.

- Morning, afternoon, and evening sessions are available for any given day.

- Organizers can avoid scheduling conflicts by coordinating planned activities with local event calendars.

- Planned activities can be combined with other local events, as appropriate.

\section{Frequency}

- Periodic meetings can be scheduled at a number of different intervals, the most common being monthly, quarterly, semi-annually, and annually.

- Meetings can also be held at irregular intervals, to respond to key events like the issuance of proposed decisions and alternatives, draft decisions, and final decisions.

\section{Location}

Activities can be held at many different locations, with the attractiveness of each determined by its distance from local population concentrations, its ease of accessibility, its capacity, and the comfort afforded by its facilities. Common locations include: 
- DOE site

- DOE public information office

- Local schools and colleges

- Public libraries

- Other local government buildings

- Restaurants, halls, malls, or other private meeting facilities

- Churches

- Local EM advisory board office

- Stakeholders" homes or offices

\section{TYPES OF PUBLIC PARTICIPATION ACTIVITIES UTILIZED}

A wide variety of public participation activities are available, with the appropriateness of each determined by a number of factors, including the types of individuals and groups involved, the needs and priorities of those participants, the type of EM activity underway, and its stage of completion. At the nine case study sites, the following activities were represented:

- Large public meetings or regulatory hearings

- Break-out sessions at large public meetings

- Small meetings or workshops, typically focusing on a specific issue or involving a specific stakeholder group

- Citizens' advisory boards or site-specific advisory boards (and associated subcommittees), which meet on a regular basis to address policy issues relative to the entire suite of EM activities

- Task forces or working groups (and subcommittees), which meet regularly to address policies and actions relative to a specific EM effort

- "Availability sessions" hosted by the EM office, which serve as a sort of "open house" for stakeholders

- Presentations or briefings by EM representatives to specific stakeholder groups

- One-on-one contacts, either formal or informal, between site employees and individual citizens, between EM managers and officials of key groups, or between any combination of these stakeholders

- EM site tours, often involving question and answer sessions

- Written and oral comments by the public and stakeholder groups in response to EM plans or documents 


\section{Internal Distribution}

1-50. S. A. Carnes

51. G. E. Courville

52. S. G. Hildebrand

53. D.W. Lee

$54 . \quad$ C. I. Moser

55-79. J. F. Munro

$80 . \quad$ M.E. Musolf

81-105. E. B. Peelle

106. R. M. Reed

$107 . \quad$ D. E. Reichle

108-132. M. Schweitzer

133. R. B. Shelton

134. B. E. Tonn

135-159. A. K. Wolfe

160. ORNL Patent Office

161. Central Research Library

162. Document Reference Section

163-64. Laboratory Records

165. Laboratory Records (Record Copy)

\section{External Distribution}

166. Dr. Lilia A. Abron, President, PEER Consultants, P.C., 1000 N. Ashley Drive, Suite 312, Tampa, FL

167-176. Mr. Don M. Beck, Deputy Director, Office of Intergovernmental and Public Accountability, U.S. Department of Energy, EM-22, 1000 Independence Avenue, S.W., Washington, D.C. 20585

177. Dr. Judith Bradbury, Pacific Northwest Laboratory, 901 D Street, S.W., Suite 900, Washington, D.C. 20024-2115

178. Dr. Kristi Branch, Battelle Seattle Research Center, 4000 N.E. 41 st Street, Seattle, Washington 98105

179. Ms. de'Lisa S. Bratcher, U.S. Department of Energy, Savannah River Operations Office, P.O Box A, Aiken, SC 29802

180. Dr. Thomas E. Drabek, Professor, Department of Sociology, University of Denver, Denver, Colorado 80208-0209.

181. Ms. Virginia Gardner, U.S. Department of Energy, Savannah River Operations Office, SRS Road 1, Aiken, SC 29802

182. Mr. Jack Hoopes, Jacobs Engineering, 1880 Waycross Road, Cincinatti, Ohio 45240

183. Mr. Chuck Hundertmark, Jacobs Engineering, 2155 Louisiana Blvd., N.E., Suite 1000 , Albuquerque, NM 87110

184. Dr. H. Jenkins-Smith, 1805 Sigma Chi Road, N.E., Albuquerque, NM 87131 
185. Mr. Steve McCracken, U.S. Department of Energy, Weldon Spring Site Remedial Action Project, 7295 Highway 94 South, St. Charles, MO 63303

186. Ms. Beth Oms, U.S. Department of Energy, Kirtland Area Office, MS-0184, 1515 Eubank, S.E., Albuquerque, NM 87123

187. ORNL Site Manager, Department of Energy, Oak Ridge National Laboratory, Post Office Box 2008, Oak Ridge, Tennessee 37831-6269

188. Ms. Sandra Perkins, U.S. Department of Energy, Oak Ridge Operations Office, P.O. Box 2001, Oak Ridge, TN 37831

189. Mr. Walter Perry, U.S. Department of Energy, Oak Ridge Operations Office, P.O. Box 2001, Oak Ridge, TN 37831

190. Ms. Bobbie G. Smith, U.S. Department of Energy, EM-433, 1000 Independence Avenue, S.W., Washington, D.C. 20585

191. Mr. George F. Sowers, P.E., Senior Vice President, Law Companies Group, Inc., 114 Townpark Drive, Suite 250, Kennesaw, Georgia 30144-5599

192. Ms. Judy Stroud, U.S. Department of Energy, Oak Ridge Operations Office, P.O. Box 2001, Oak Ridge, TN 37831

193. Mr. Jim E. Tarro, Vice President, Technology Commercialization, Applied Sciences Laboratory, Inc., P.O. Box 11069, Burke, VA 22009-1069

194. Dr. Susan F. Tierney, The Economics Resource Group, Inc., One Mifflin Place, Cambridge, MA 02138-4946

195. Dr. Seth Tuler, CENTED, Clark University, 950 Main Street, Worcester MA 01610

196. Ms. Michelle D. Ulick, Science Applications Intternational Corporation, 101 Convention Center Drive, Suite P105, Las Vegas, NV 89109

197. Dr. C. Michael Walton, Ernest H. Cockrell Centennial Chair in Engineering and Chariman, Department of Civil Engineering, University of Texas at Austin, Austin, Texas 78712-1076.

198. Weldon Spring Citizen Commission, 100 N. Third St., Room 107, St. Charles, MO 63301

199-200 OSTI, U.S. Department of Energy, P.O. Box 62, Oak Ridge, Tennessee 37831 